\title{
Review \\ Definition, Epidemiology, Pathophysiology, and Essential Criteria for Diagnosis of Pediatric Chronic Myeloid Leukemia
}

\author{
Meinolf Suttorp ${ }^{1, *(\mathbb{D})}$, Frédéric Millot ${ }^{2}$, Stephanie Sembill ${ }^{3}$, Hélène Deutsch ${ }^{2}$ and Markus Metzler $^{3}$ (D) \\ 1 Pediatric Hemato-Oncology, Medical Faculty, Technical University Dresden, D-01307 Dresden, Germany \\ 2 Inserm CIC 1402, University Hospital Poitiers, F-86000 Poitiers, France; f.millot@chu-poitiers.fr (F.M.); \\ Helene.DEUTSCH@chu-poitiers.fr (H.D.) \\ 3 Pediatric Oncology and Hematology, Department of Pediatrics and Adolescent Medicine, \\ University Hospital Erlangen, D-91504 Erlangen, Germany; Stephanie.Sembill@uk-erlangen.de (S.S.); \\ Markus.Metzler@uk-erlangen.de (M.M.) \\ * Correspondence: meinolf.suttorp@uniklinikum-dresden.de; Tel.: +49-351-458-3522; Fax: +49-351-458-5864
}

check for updates

Citation: Suttorp, M.; Millot, F.; Sembill, S.; Deutsch, H.; Metzler, M. Definition, Epidemiology,

Pathophysiology, and Essential Criteria for Diagnosis of Pediatric Chronic Myeloid Leukemia. Cancers 2021, 13, 798. https://doi.org/ 10.3390/cancers13040798

Academic Editors: Marc Delord and Gabriel Etienne

Received: 11 January 2021

Accepted: 8 February 2021

Published: 14 February 2021

Publisher's Note: MDPI stays neutral with regard to jurisdictional claims in published maps and institutional affiliations.

Copyright: (c) 2021 by the authors. Licensee MDPI, Basel, Switzerland. This article is an open access article distributed under the terms and conditions of the Creative Commons Attribution (CC BY) license (https:// creativecommons.org/licenses/by/ $4.0 /)$.
Simple Summary: The low incidence $(1: 1,000,000)$ of chronic myeloid leukemia (CML) in the first two decades of life presents an obstacle to accumulation of pediatric experience and knowledge on this leukemia. Biological features of CML are shared but also differing between adult and pediatric patients. This review aims; (i) to define the disease based on an unified terminology, (ii) to list the diseases to be considered as a differential diagnosis in children, (iii) to outlines the morphological, histopathological and immuno-phenotypical findings of pediatric CML, (iv) to illustrate rare but classical complications resulting from high white cell and platelet counts at diagnosis, and (v) to recommend a uniform approach for the diagnostic procedures to be applied. Evidently, only a clear detailed picture of all relevant features can lay the basis for standardized treatment approaches.

Abstract: Depending on the analytical tool applied, the hallmarks of chronic myeloid leukemia (CML) are the Philadelphia Chromosome and the resulting mRNA fusion transcript BCR-ABL1. With an incidence of 1 per 1 million of children this malignancy is very rare in the first 20 years of life. This article aims to; (i) define the disease based on the WHO nomenclature, the appropriate ICD 11 code and to unify the terminology, (ii) delineate features of epidemiology, etiology, and pathophysiology that are shared, but also differing between adult and pediatric patients with CML, (iii) give a short summary on the diseases to be considered as a differential diagnosis of pediatric CML, (iv) to describe the morphological, histopathological and immunophenotypical findings of CML in pediatric patients, (v) illustrate rare but classical complications resulting from rheological problems observed at diagnosis, (vi) list essential and desirable diagnostic criteria, which hopefully in the future will help to unify the attempts when approaching this rare pediatric malignancy.

Keywords: pediatric CML; diagnostic essential criteria; epidemiology; pathophysiology

\section{Introduction}

For a long time, the rarity of chronic myeloid leukemia (CML) in minors has hampered the accumulation of in-depth knowledge from cases presenting in the first two decades of life. Before the introduction of tyrosine kinase inhibitors (TKI) for the treatment of CML, stem cell transplantation was the recommended therapeutic approach for young patients and data on pediatric CML were deposited at the EBMT and IBMTR registries [1-3]. Given the enormous improvement of therapeutic success achieved by TKIs, the interest in the long-term outcome of this novel treatment especially in pediatric patients resulted in foundation of the International Registry on Pediatric CML (IR-PCML) at Poitiers/France in the year 2010 [4]. Since then, the number of collaboration centers and in parallel of registered patients continuously has increased. As of today, data on more than 660 patients diagnosed with CML at a median age of 12 years (range 0-17 years) have been collected. 
The information depicted from a registry on a rare disease like CML in minors offers the enormous benefit to enable treating physicians to apply a uniform approach to diagnose and follow-up this leukemia. Based on the collected data and the shared experience also in very small subcohorts (e.g., CML at very young age, diagnosis in advanced stage of disease, treatment failure) this article recommends a uniform approach for the diagnostic procedures to be applied in the management of CML in children and young adolescents.

\section{Definition of $C M L$}

CML BCR-ABL1 positive is an acquired clonal myeloproliferative hematological malignancy derived from an abnormal pluripotent bone marrow stem cell. The leukemic cell clone consistently is characterized by a specific cytogenetic anomaly the so-called Philadelphia (Ph1) chromosome representing a reciprocal chromosomal translocation $\mathrm{t}(9 ; 22)(\mathrm{q} 34.1 ; \mathrm{q} 11.2)$ which generates the BCR-ABL1 fusion gene. Cryptic translocations -being invisible on banding chromosome preparations- or variant translocations involving other chromosomes may represent an obstacle when establishing a diagnosis of CML. The presence of the Ph1 chromosome or BCR-ABL1 sharply separates CML from other myeloproliferative neoplasms (MPNs) like essential thrombocytosis (ET), polycythemia vera (PV) and idiopathic (osteo)myelofibrosis (OMF/IMF) [5]. Notably, the detection of the $\mathrm{Ph} 1$ chromosome is not sufficiently specific to diagnose CML, as it is also found in acute lymphoblastic leukemia ( $2-5 \%$ of pediatric cases of ALL).

The BCR-ABL1 is present in the bone marrow in all myeloid lineages as well as in some lymphoid cells [6,7]. Whether endothelial cells of the bone marrow niche are BCR-ABL1 positive is a matter of debate [8-10]. Morphologically, CML is characterized by a hypercellular bone marrow, an unregulated growth of myeloid cells (neutrophils, eosinophils, basophils and megakaryocytes) resulting in abnormally high level of morphologically terminally differentiated granulocytes, as well as myeloid precursor cells in the blood and is associated with splenic enlargement in $>60 \%$ of affected children.

The term "Pediatric" CML does not only indicate the age of a patient affected from CML BCR-ABL1 but also points to distinct biological features (see below Section 9) which are observed with decreasing frequency from the 3rd to 6th decade of life. The latter represents the age when CML BCR-ABL1 is typically diagnosed in Caucasian adults.

\section{Related Terminology and ICD Codes}

Synonyms of CML BCR-ABL1 positive are listed in Table 1. These terms are based on the laboratory method used to establish the diagnosis (based on chromosomal analysis or on molecular technique) and the terms to describe the myeloproliferative characteristics in histological findings. The term "myeloid" should be used in the English literature on pediatric CML for the sake of brevity and replace the terms "granulocytic" or "myelogenous". The term "Juvenile CML" should not be used at all to avoid any possibility of confusion and mixing-up pediatric CML with the completely different entity of juvenile myelomonocytic leukemia (JMML) [11]. JMML is a unique pediatric disorder also different from chronic myelomonocytic leukemia (CMML) in adults $[5,12,13]$.

The WHO's system for International Classification of Diseases (ICD) in the present version of ICD11 recommends the codes as listed in Table 2 for categorization of CML. These codes do also apply in children with CML. 
Table 1. Synonyms of chronic myeloid leukemia (CML), BCR-ABL1 positive.

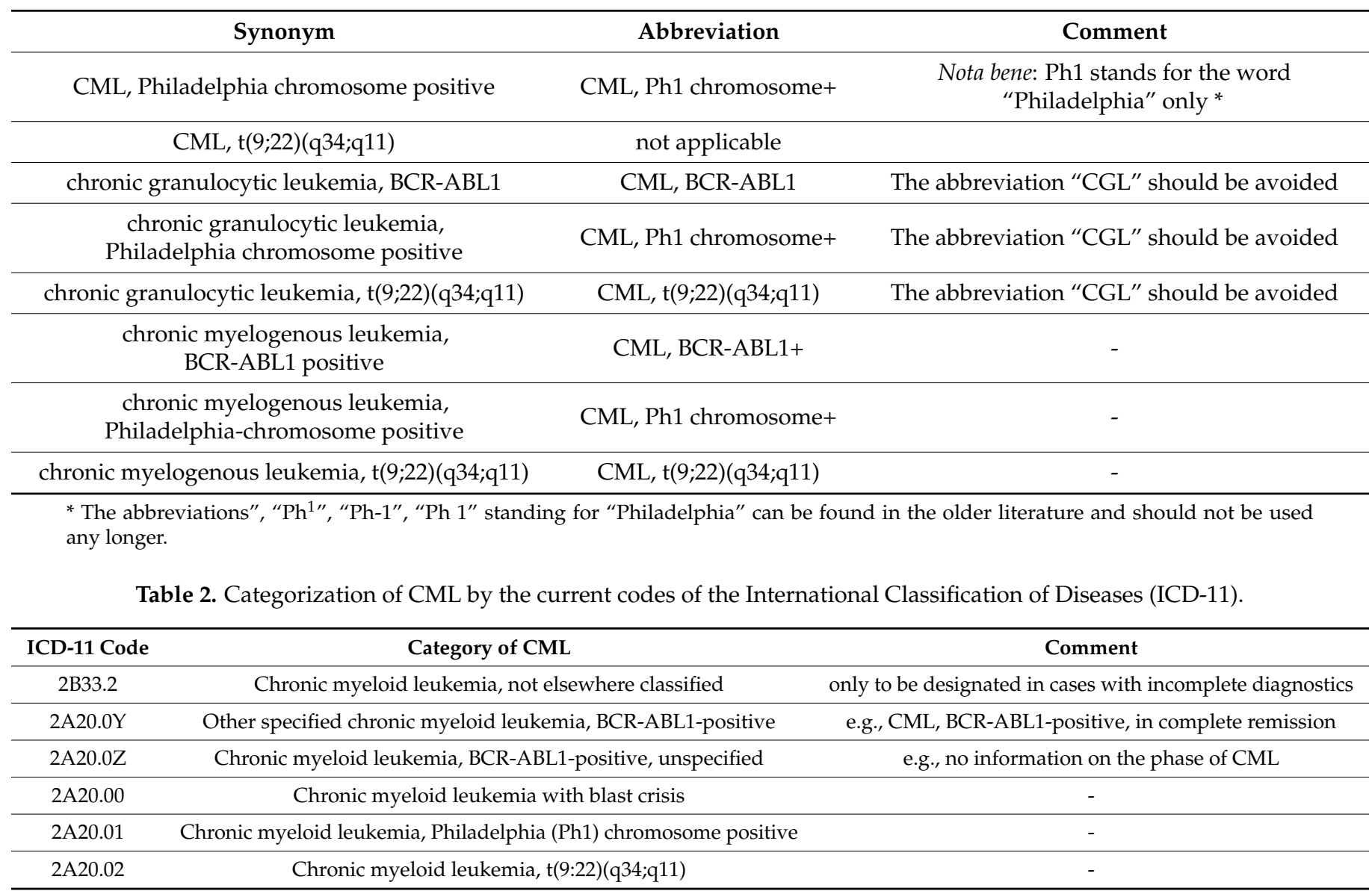

\section{Staging and Classification of CML by Phases}

Historically, based on the quantity of blasts, CML is categorized into three progressive phases driving the aggressiveness of the disease.

- Chronic phase (CML-CP) is the most common, indolent clinical stable phase of CML lasting for several years. The myeloid cells are differentiated, with less than $10 \%$ of blast cells present in the bone marrow. The response to therapy is excellent.

- If untreated, CML-CP usually progresses to the accelerated phase (CML-AP). The cells multiply aggressively and the blast cells increase to $10-19 \%$. Additional chromosomal aberrations beside the $\mathrm{Ph}+$ may be detectable [14]. The response to therapy becomes poorer.

- $\quad$ From CML-AP the leukemia progresses to a blastic phase (CML-BP) which is indistinguishable from acute leukemia exhibiting $>20 \%$ (or $\geq 30 \%$, see below) of bone marrow blasts of either myeloid or lymphoid immunophenotype. The response to therapy is very poor.

Logically the identification of the phase of CML forms the basis for treatment planning. However, the quantitative morphological criteria as established by the WHO $[15,16]$ and the European LeukemiaNet (ELN) [17] as listed in Table 3 differ for CML-AP and CML-BP. For example, the WHO-recommended criteria for CML-BP are $\geq 20 \%$ of blast cells in blood or bone marrow, extramedullary blast proliferation, or large foci or clusters of blasts in the bone marrow biopsy while the ELN threshold is set to $30 \%$ of blasts. In adults, the borderline range has a clinical impact as in a comparative analysis, adult patients who had a blast percentage of $20-29 \%$ which is considered CML-BP according to the WHO classification, had a significantly better response rate $(21 \% \mathrm{vs.} 8 \%)$ and 3-year survival rate ( $42 \%$ vs. $10 \%$ ) compared with patients who had blasts $\geq 30 \%$ [18]. 
Table 3. Comparison of the criteria established by the ELN and the WHO for definition of the phase of CML.

\begin{tabular}{|c|c|c|}
\hline \multicolumn{3}{|r|}{ Definition as Used by } \\
\hline Phase & European LeukemiaNet (ELN) & World Health Organization (WHO) \\
\hline CML CP & $\begin{array}{l}-\quad<10 \% \text { blasts in PB or in BM } \\
\text { - } \quad \text { No criteria fulfilled for } \\
\text { CML-AP or CML-BP }\end{array}$ & $\begin{array}{l}\text { - } \quad<10 \% \text { blasts in PB or in BM } \\
\text { - } \quad \text { No criteria fulfilled for CML-AP or CML-BP }\end{array}$ \\
\hline CML-AP & $\begin{array}{l}\text { Persistent thrombocytopenia } \\
\left(<100 \times 10^{9} / \mathrm{L}\right) \text { unrelated to } \\
\text { therapy } \\
>20 \% \text { basophils in the PB } \\
\text { - } \quad 15-29 \% \text { blasts in the PB } \\
\text { and } / \text { or BM } \\
\text { Sum of myeloblasts and } \\
\text { promyelocytes }>30 \% \text { in the PB } \\
\text { or BM with proportion of } \\
\text { blasts }<30 \%\end{array}$ & 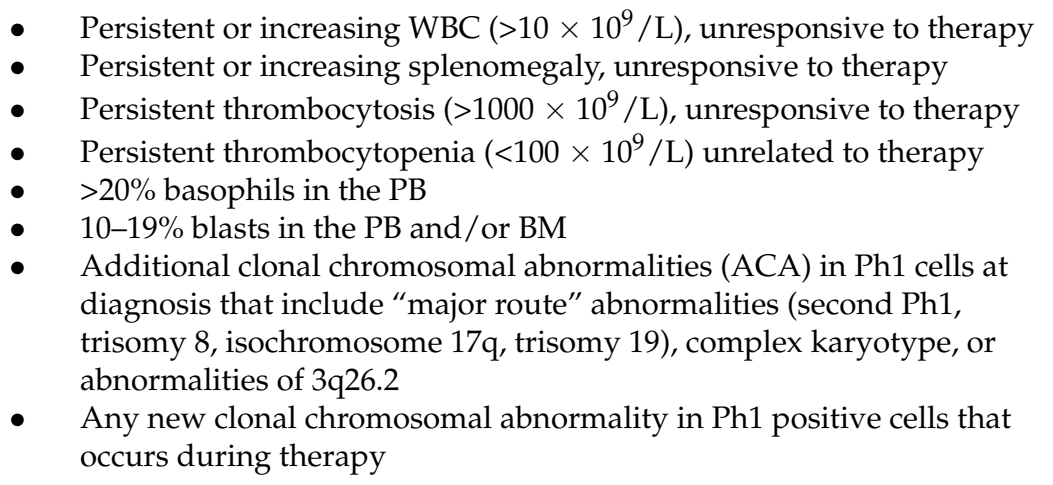 \\
\hline CML-BP & $\begin{array}{l}\text { - } \quad \geq 30 \% \text { blasts in the blood, } \\
\text { marrow or both } \\
\text { Extramedullary infiltrates of } \\
\text { leukemic cells (with the } \\
\text { exception of spleen and liver) }\end{array}$ & $\begin{array}{l}\text { - } \\
\text { the presence of an extramedullary accumulation of blasts (with the } \\
\text { exception of spleen and liver) } \\
\text { (As the onset of lymphoid BP may be quite sudden, the detection of any } \\
\text { bona fide lymphoblasts in the blood or marrow should raise con-cern } \\
\text { for a possible impending lymphoid BP, and prompt additional } \\
\text { laboratory and genetic studies to exclude this possibility). }\end{array}$ \\
\hline
\end{tabular}

In the TKI era, treatment response may also be used to classify CML-AP (provisional WHO definition) [15] such as:

- hematologic resistance to the first TKI (or failure to achieve a complete hematologic response to the first TKI) or

- any hematological, cytogenetic, or molecular indications of resistance to 2 sequential TKIs or

- $\quad$ occurrence of 2 or more mutations in BCR-ABL1 during TKI therapy

The ELN criteria have been recommended previously [19] by the international BerlinFrankfurt-Muenster (BFM) group also for pediatric CML as these criteria have been used in the majority of randomized clinical trials when treating CML in adults with TKI. Guidelines recently published by the Children's Oncology Group from North America [20] are using the criteria of the National Comprehensive Cancer Network (NCCN) [21] which are derived from the WHO criteria.

In addition, it should be noticed that the introduction of new treatments could change the boundaries between $\mathrm{CP}, \mathrm{AP}$, and $\mathrm{BC}$, and modify to some extent the classic subdivision of CML into three phases. Both classification systems agree on that independently from the proportion of blasts any extramedullary infiltration of organs beside liver and spleen in CML must be classified as blastic phase.

\section{Subtypes of CML}

One large breakpoint region (approx. $200 \mathrm{~kb}$ ) is found in the ABL1 gene on chromosome $9 \mathrm{q} 34$ whereas three breakpoint regions are present in the so-called breakpoint cluster region (BCR) gene on chromosome 22q11 (Figure 1). Like in adults, in pediatric CML the vast majority of breakpoints cluster in a small region of the major (M-bcr) breakpoint while alternate, less common breakpoints cluster in the minor bcr $(\mathrm{m}-\mathrm{bcr})$ and very rarely further upstream in the BCR gene, in the so-called micro bcr ( $\mu$-bcr) [22-24]. M-bcr, $\mathrm{m}$-bcr, and $\mu$-bcr are associated with the p190, p210 and p230 BCR-ABL1 fusion proteins, 
respectively [25]. These three well-defined breakpoint regions in the BCR gene can produce at least eight different m-RNA fusion transcripts (M-bcr, p210: e14a2, e13a2, e14a3, e13a3; m-bcr, p190: e1a2, e1a3; $\mu$-bcr, p230: e19a2, e19a3) because of alternative splicing in the ABL1 gene (splicing to exon 2 or exon 3 ) and because the M-bcr consists of two intronic regions (intron 13 and intron 14) $[25,26]$.

\section{Chrom. 9q34}

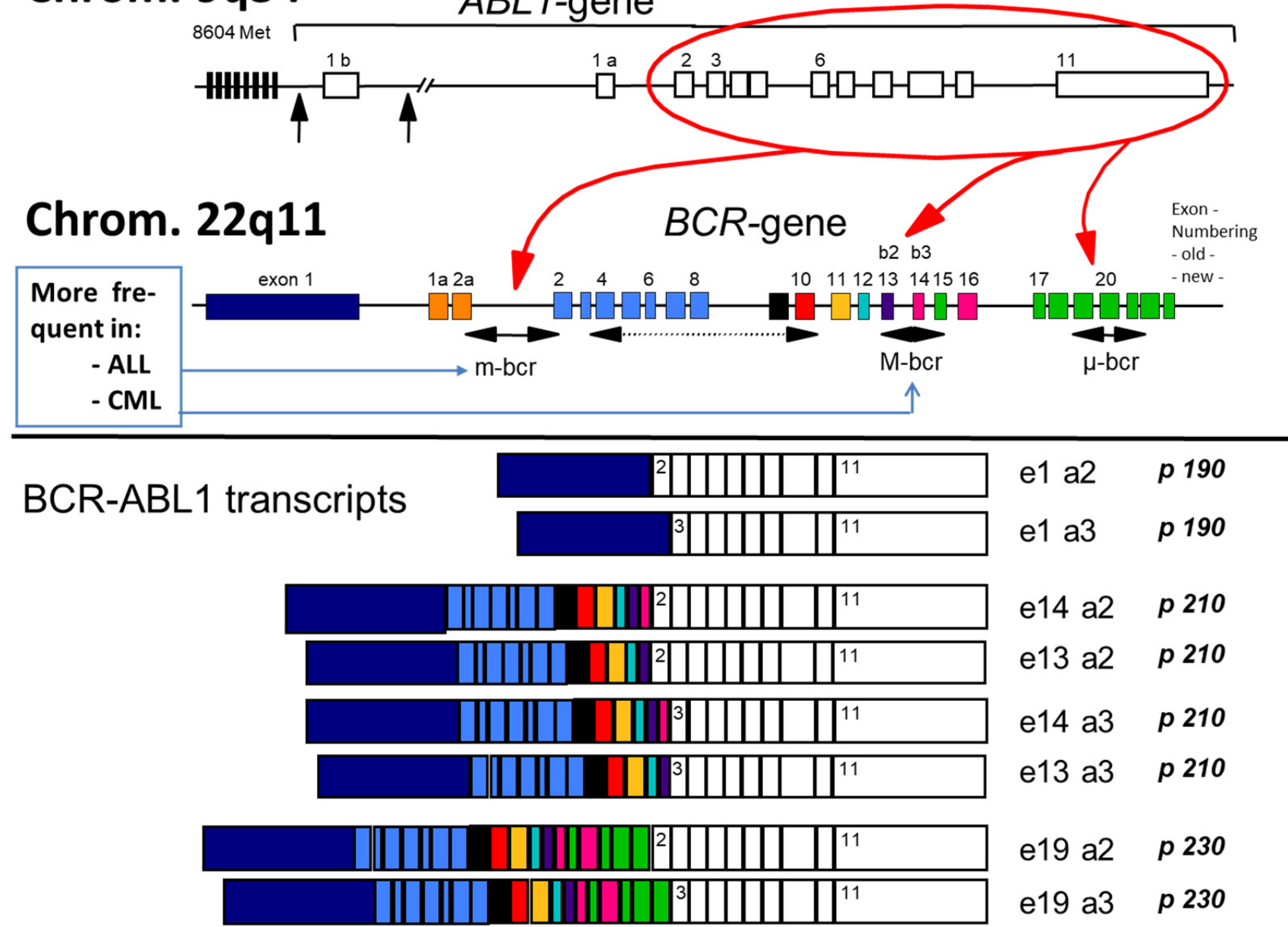

ABL1-gene

Figure 1. Gene breakpoints and resulting transcript types. Intronic breakpoints (vertical black arrows) of the ABL1 gene and intronic breakpoints of the BCR gene (black horizontal arrows) and the corresponding fusion proteins (Length of exons and introns not according to scale). Pseudoexons $1 \mathrm{a}$ and $1 \mathrm{~b}$ on the ABL-gene as well as pseudoexons $1 \mathrm{a}$ and $2 \mathrm{a}$ on the BCR-gene are spliced out. In CML, the most frequently observed M-bcr breakpoint and the less frequently and only rarely observed breakpoints $\mathrm{m}$-bcr and $\mu$-bcr, respectively, can produce eight $\mathrm{m}$-RNA fusion transcripts and translated proteins because of alternate splicing of the ABL1-gene exon 2 and because of two internal breakpoints in intron 13 and intron 14 of the BCR-gene. Additional breakpoints (indicated by a dotted horizontal arrow in this cartoon) have been described rarely or only as single case.

In CML-CP, the transcript types e13a2 and e14a2 are present with a frequency of $95 \%$. In a single center study on pediatric CML ( $\mathrm{N}=146$ patients), a proportion of $38 \%$ patients harbored transcript type e $13 \mathrm{a} 2$ and $36 \%$ transcript e14a2 while the remaining $26 \%$ patients expressed both transcripts due to alternate splicing [22]. In a worldwide analysis on patients of all ages ( $\mathrm{N}=45,503$ patients) transcript e13a2 is detected more frequently in males (39.2\%) than in females (36.2\%) and correlates with age, decreasing from $39.6 \%$ in children and adolescents down to $31.6 \%$ in patients $\geq 80$ years old [27]. Whether or not differences resulting from the presence of either transcript e14a2 or e13a2 exert a possible impact on the treatment response is discussed below in the Section 16. In addition, several 
very rare BCR-ABL1 variant fusion genes (resulting in the p195, p200 and p225 BCR-ABL1 fusion proteins; fusion transcripts e6a2, e8a2, and e18a2, respectively) have been detected -partly in single cases [26-30].

\section{Differential Diagnosis}

If CML is suspected but the Ph1 chromosome and BCR-ABL1 fusion transcript are absent, non-malignant disorders with a clinical and hematological picture mimicking CML need to be excluded first. Leukemoid reaction (LR) is the major differential diagnosis of CML in patients presenting with a leukocyte count in the range of 50,000 cells $/ \mu \mathrm{L}$ and significant increase in mature neutrophils with a marked shift to the left [31]. Laboratory findings like toxic granulocytic vacuolation, Döhle's bodies in the granulocytes, absence of basophilia, and a normal or increased leukocyte alkaline phosphatase (LAP) score separate the LR from CML [32]. Basophils are normal in LR and splenomegaly is an unusual finding. Taking carefully the clinical history and physical examination is suggestive of the origin of the LR, which is very heterogeneous comprising infections (especially S. aureus, S. pneumoniae), inflammatory syndromes (e.g., glomerulonephritis), malignancies, drugs (corticosteroids can cause a short-lasting extreme left-shifted neutrophilia), intoxications (liver failure), severe hemorrhage, and acute hemolysis [33].

Without karyotyping, CML may be more difficult to differentiate from the other classical myeloproliferative neoplasms (MPNs) occurring in adults which are comparatively uncommon in children. Polycythemia vera (PV) with associated iron deficiency (e.g., teenage girls with hypermenorrhagia), which causes normal hemoglobin and hematocrit values, can manifest with leukocytosis and thrombocytosis. Isolated megakaryocytic hyperplasia can be seen in Essential Thrombocythemia (ET) with marked thrombocytosis and splenomegaly. Such patients usually have a normal or increased LAP score, a WBC count less than 25,000/ $\mu \mathrm{L}$, and no Ph1 abnormality. However, concerning the typical mutations a lower incidence of mutation JAK2-V617F has been reported in childhood ET and PV, and fewer CALR mutations were found in children with ET [34]. Primary (osteo)myelofibrosis (PMF) also termed idiopathic myelofibrosis (IMF) is extremely rare in children [35], although sporadic childhood cases with PMF/IMF have been described [36]. Compared to adults, phenotypic differences appear to exist in children with PMF/IMF which are typically also found in pediatric CML, such as a frequent presence of marrow eosinophilia, only a low degree of marrow collagen fibrosis, the absence of significant osteosclerosis and megakaryocytic dysplasia with hypolobulated megakaryocytes with hyperchromatic nuclei and micromegakaryocytes. Notably, in none of 40 cases pediatric cases with IMF reported worldwide a previously described mutation, such as JAK2-V617F has been identified [37].

Virtually all cases of pediatric Myelodysplastic Syndrome (MDS) present with pancytopenia involving all three cell lineages, while single lineage cytopenia or macrocytosis may occasionally be the presenting findings [5]. Contrasting CML, leukocytosis is generally not a feature of MDS. Some patients may present with moderate hepatosplenomegaly but most have no organomegaly. Cytogenetic aberrations (monosomy 7, trisomy 8, 5q-, trisomy 21) are found in 55\%-75\% children with MDS. In childhood, the bone marrow may be hypo- or normocellular but rarely hypercellular. While small megakaryocytes are also found in CML, typical dysplastic features like macrocytic erythropoiesis, unusually large megakaryocytes, and dysgranulopoiesis point towards MDS but are not found in CML.

Juvenile Myelomonocytic Leukemia (JMML) typically manifests in infants and thereafter until the fifth year of life with declining incidence. Patients present with fever, infection, pallor, bleeding, hepato- or splenomegaly, lymphadenopathy, and skin rash [5]. The blood smear is characteristic showing uniformly elevated WBC count with absolute mo-nocytosis, anemia, and thrombocytopenia and is often more helpful in diagnosing than the BM morphology in which monocytosis is often only discrete. An additional finding not detected in CML is an increased $\mathrm{HbF}$ in patients with normal karyotype [11]. Mutations are found in the Ras signal transduction pathway downstream of the receptor in about 
90\% of patients; thus, JMML belongs to the group of diseases called RASopathies (Noonan syndrome, CBL-syndrome, NF1) [38].

Extremely rarely, pediatric patients may present with myeloid hyperplasia, which involves almost exclusively the neutrophil, eosinophil, or basophil cell lineage. These patients are described as having chronic neutrophilic, eosinophilic, or basophilic leukemia and do not have evidence of the Ph1 chromosome or the BCR-ABL1 gene. The World Health Organization defines MPD with eosinophilia and constitutively activated plateletderived growth factor receptor- $\alpha$, or $-\beta$, or fibroblast growth factor receptor 1 as a distinct category [39]. Occasionally, these myeloid neoplasms present in the first years of life with leukocytosis and organomegaly, and thus need to be differentiated from JMML or CML with increased eosinophils [11].

\section{Epidemiology}

CML usually presents at a median age of 60 years in Caucasians, but at younger age (35-45 years) in Asians [40-42]. It is rare in children contributing only $2-3 \%$ of all pediatric leukemia cases. The global incidence rate of CML is $15 / 1,000,000$ per year with a male to female ratio of 1.34 while the age-adjusted incidence rate for the age group $<18$ years is 1.0 per 1,000,000 [43]. In the first three years of life pediatric CML is extremely rare [44]. The SEERS database showing pooled data on all myeloproliferative diseases at childhood age lists a continuously increasing incidence rate from 0.7 cases in the age group 1 to 4 years up to 4.3 cases per $1,000,000$ at 15 to 19 years (Table 4). From the authors' experience, myeloproliferative diseases besides CML like essential thrombocytosis, polycythemia vera and myelofibrosis are more than 10-fold less frequent than CML in the first two decades of life. Therefore, the SEERS data give a rather detailed impression on the continuous increase in the incidence of CML especially in the 2nd decade of life.

Table 4. Age adjusted and age specific incidence rates (per 1,000,000 children) of chronic myeloproliferatice diseases (all races, males and females) depicted from the SEERS database listing data from the USA in the years 2011-2015. [45].

\begin{tabular}{cccccccc}
\hline Age (Years) & $\mathbf{0 - 1 4}$ & $\mathbf{0 - 1 9}$ & $<\mathbf{1}$ & $\mathbf{1 - 4}$ & $\mathbf{5 - 9}$ & $\mathbf{1 0 - 1 4}$ & $\mathbf{1 5 - 1 9}$ \\
\hline Chronic Myeloproliferative Diseases & 1.4 & 2.1 & - & 0.7 & 1.0 & 2.1 & 4.3 \\
\hline
\end{tabular}

\section{Etiology}

Predisposing factors to pediatric CML are not known. Ionizing radiation is considered a rare risk factor in adults. The maximum increase in $\mathrm{CML}$ incidence was observed in atomic bomb survivors in Hiroshima after a median time of 6 years, however, not after the Chernobyl nuclear power plant accident. Probably only exposure to higher radiation doses causes CML. Following irradiation and/or chemotherapy applied in the context of the treatment of a malignancy-mostly Hodgkin and Non-Hodgkin lymphomas-CML has been observed as secondary malignancy rarely in some adult and pediatric cases [46-49]. As the incidence of pediatric CML is not increased in healthy siblings, and especially not in twin pairs with one child affected from CML, genetic factors are of greater importance in the etiology of CML [50-53]. The role of mutated so-called myeloid "driver" genes is increasingly getting into the focus in pediatric CML [54,55].

\section{Pathogenesis}

The acquisition of BCR-ABL1 in a hematopoietic stem cell drives its transformation to become a leukemic stem cell (LSC). The fusion protein BCR-ABL1 represents a constitutive active tyrosine kinase considered to be the pathogenic driver capable of initiating and maintaining the disease. BCR-ABL1 activates a number of oncogenic signaling pathways, including PI3K/AKT/mTOR, RAS/RAF/MEK/ERK, and JAK/STAT [56]. However, numerous papers have described that the BCR-ABL1 oncogene does not operate alone when driving disease emergence, maintenance, and progression [57,58]. In children with $\mathrm{CML}$, the myeloid driver mutation ASXL1 is found more frequently than in adult CML [54]. 
Additional biological differences in adult CML comprise a single breakpoint cluster within the first centromeric $1.5 \mathrm{~kb}$ of the BCR gene, whereas in pediatric CML there is a bimodal breakpoint distribution which is similar to adult Ph+ ALL harboring the less frequently observed M-BCR rearrangement [59]. In pediatric CML the bimodal breakpoint distribution in the BCR gene changes to the adult pattern at the age of 13 years, probably in association with the onset of puberty (Figure 2). For so far unknown reasons, the adult type breakpoint distribution pattern at prepubertal age is found more frequently in girls, but not in boys. We hypothesize that there are uncharacterized sex differences in the non-coding regions of the genome on which changes in the sex hormone blood levels starting at puberty exert an influence.

\section{Pediatric CML $(\mathrm{n}=102)$}

A

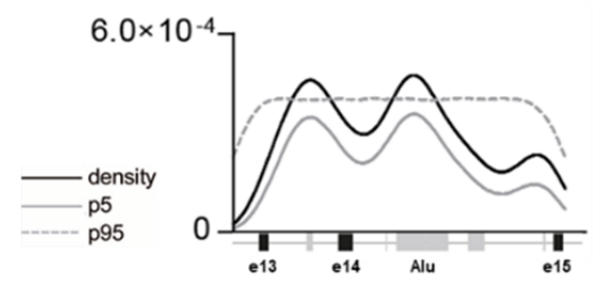

Adult CML $(n=308)$

$B C R$

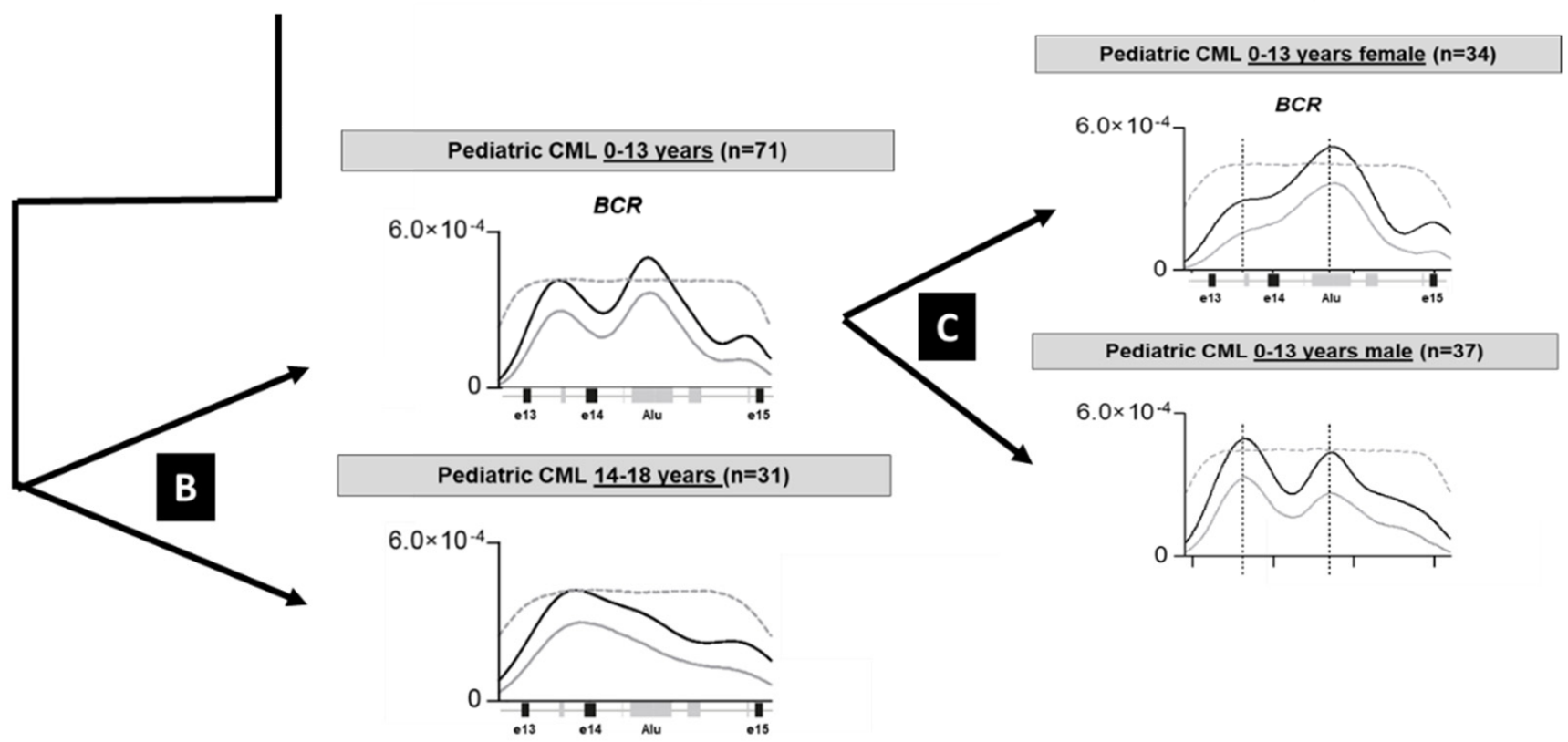

Figure 2. Illustration of the genomic DNA breakpoint distribution in the BCR gene and Kernel density analysis. For details see reference [59]. (A) When the pattern in 102 pediatric patients with CML is compared to 308 adult patients with CML as reported in the literature, pediatric CML shows a bimodal distribution which is also found in Ph1 positive acute lymphoblastic leukemia. (B) The bimodal "ALL-type" breakpoint can be found more frequently in prepubertal children and (C) in the prepubertal cohort is detectable more frequently in boys. In the Kernel plots the gray lines denote the 5\% and the dotted line the $95 \%$ confidence intervals. 
In pediatric acute leukemias the origin of the malignant cell clone has been traced back to its development in utero by using dried blood spots archived at birth on Guthrie cards $[60,61]$. The first case of pediatric CML in which BCR-ABL1, but no blood abnormalities were present at birth was identified recently from an archived cord blood specimen retrospectively when the infant presented with CML-CP at the age of 6 months [62]. A high-sensitive technique using nested genomic DNA-based PCR with subject-specific PCR primers after characterizing the genomic breakpoints $[59,63,64]$ identified a clonal burden of less than 1 in 10,000 leukocytes at birth. In this case, a mutation associated with predisposition to several myeloid cancers was ruled out based on a defined myeloid panel of 11 driver genes (ACD, ANKRD26, CEBPA, DDX41, ETV6, GATA2, RUNX1, SRP72, TERC, TERT, and TP53). If all cases of CML - like acute leukemias- would also take their origin already in utero the observed sex difference at puberty concerning the BCR breakpoint could hardly be explained.

BCR-ABL1 can also be detected -rarely but with age-dependent increase from newborn to older age- in blood specimen collected from healthy individuals [65]. Thus, the dogma of BCR-ABL1 representing the sole event initiating CML is challenged [66]. In all patients receiving long-term TKI-treatment, CML-LSCs persist as they are resistant to the effects of TKIs. Bone marrow microenvironment-generated signals, cell autonomous BCR-ABL1 kinase-independent genetic changes, and epigenetic alterations all contribute to: (i) persistence of a quiescent LSC reservoir, (ii) innate or acquired resistance to TKIs, and (iii) progression into the fatal blast crisis stage $[67,68]$.

\section{Clinical Features and Hematological Findings}

There are no organ alterations protruding as signs specific for CML. The bone marrow and blood are generally involved in pediatric CML. Besides hypersplenism, CML may cause fever, infection, easy bleeding, mild normocytic anemia, fatigue, bone pain, or other unspecific symptoms $[44,69,70]$. Compared to adults, pediatric CML-CP presents with more aggressive clinical and biological features such as a higher proportion of patients exhibiting splenomegaly, a larger spleen size, and higher leukocyte and platelets counts [69,71-73].

More than $90 \%$ of all pediatric patients with CML are diagnosed in CML-CP. The proportion of children in advanced phases (CML-AP and CML-BP) represents only 7.5\% of all patients according to the International Registry for Childhood CML [4,74]. Because of leukemic infiltrates the spleen is enlarged in $70 \%$ to $80 \%$ and the liver in $50 \%$ to $60 \%$ of pediatric patients in CML-CP $[69,70,75]$. In CML-BP, however, any tissue (lymph nodes, skin, soft tissue, bones, and CNS) may be infiltrated by blasts [76]. Solid extramedullary manifestations of CML historically are termed chloroma because of the greenish color caused by the presence of myeloperoxidase [77]. Significantly, any extramedullary organ infiltration (except of spleen, liver, or retinal infiltration) results in upstaging a patient from CML-CP or CML-AP to CML-BP. CNS infiltration is not seen in CML-CP but the diagnosis of CML-BP requires i.th. prophylactic treatment $[19,78]$.

CML is diagnosed in one third of pediatric patients incidentally when a blood count is performed to clarify other medical conditions [70,79]. Compared to adult CML, the mean leukocyte count in pediatric CML at diagnosis is more than four-fold higher $\left(60 \times 10^{9}\right.$ cells $/ \mathrm{L}$ versus $240 \times 10^{9}$ cells $\left./ \mathrm{L}\right)[70,71,79,80]$. Therefore, once anticoagulated blood from pediatric patients with CML is allowed to separate into cellular elements and plasma, a broad "buffy coat" ("leukocrit") overtopping the size of the hematocrit is usually visible. Mild normocytic, normochromic anemia (median $\mathrm{Hb} 10.4 \mathrm{~g} / \mathrm{dL}$ ) is present at diagnosis in $60 \%$ pediatric patients in CML-CP $[69,70]$.

The WBC differential usually shows granulopoietic cells at all stages of maturation, from myeloblasts to mature, morphologically normal granulocytes. This "pathological shift to the left" is typical for CML and as outlined in Figure 3 easily allows the separation from other conditions like reactive shift to the left caused by infections or from AML with presence of blasts but missing more mature granulopoietic cells (hiatus leucemicus). Neutrophil function in CML is normal or only mildly impaired. These mature granulocytes 
have decreased apoptosis, resulting in accumulation of long-lived cells with low or absent enzymatic activity, such as alkaline phosphatase. Basophils are usually elevated in the range of $5 \%$ to $10 \%$ in the peripheral blood and eosinophils may be mildly increased as well.

Contrasting findings in acute leukemias, the platelet count is normal in CML-CP and even elevated above $500 \times 10^{9} / \mathrm{L}$ in half of the pediatric patients [81]. Thrombosis results extremely rarely from this alteration -instead mucocutaneous bleeding is observed in more than $10 \%$ children with elevated platelet counts. Bleeding is caused by a reduced plasma concentration of large Von Willebrand (VW) factor multimers, indicating a diagnosis of acquired VW-syndrome, which resolves after initiation of CML treatment. Platelet function abnormalities like Glanzmann thrombasthenia in CML at diagnosis have also been described in the literature [82].

During the accelerated phase of CML the proportion of immature cells increases and thrombocytopenia usually develops. Basophils may increase, and granulocyte maturation becomes defective.
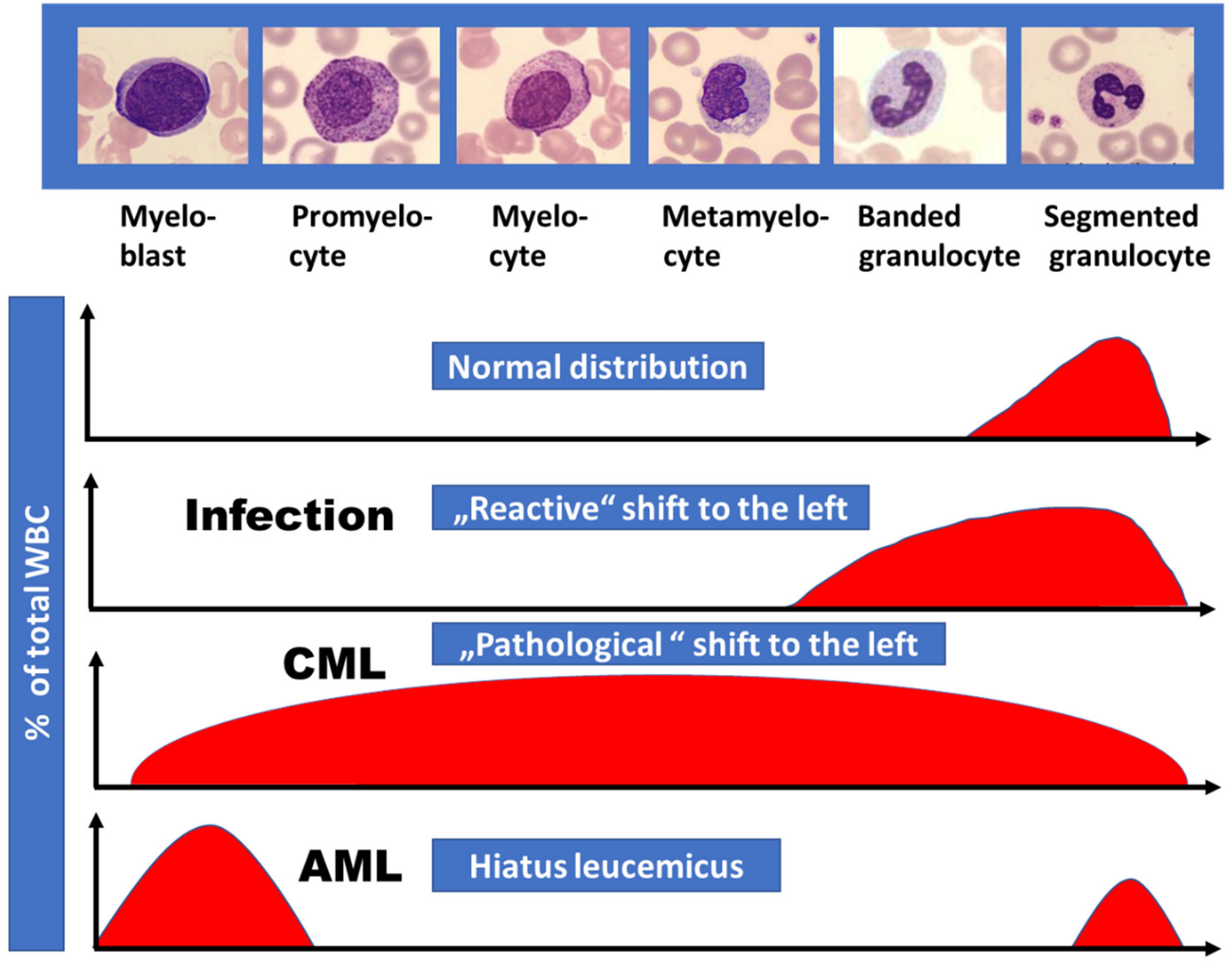

Figure 3. Proportion of immature granulopoietic cells ("shift to the left") as observed in the differential white cell count in different diseases. Compared to the reactive shift to the left in bacterial infectious diseases, CML is characterized by the presence of more immature granulopoietic cells in addition including myeloblasts. In AML "hiatus leucemicus" (Latin, meaning "leukemic gap") usually is observed exhibiting myeloblasts and mature granulocytes only. 


\section{Rheological Problems Associated with High White Cell and Platelet Count}

Despite the high white cell count in children at diagnosis, rheological problems are observed in less than $10 \%$ of children presenting with an extremely high median WBC of $458,000 / \mu \mathrm{L}$ [83]. Carefully history taking and physical examination is required in children admitted with CML because aside from typical symptoms of leukostasis like dyspnea, headache and dissziness, also blurred vision due to retinal bleeding and infiltrates with leukemic cells (Figure 4) (generally reversible within months) [84] can be observed, as well as low flow/venoocclusive priapism in boys (caveat: emergency scenario to avoid irreversible erectile dysfunction) [85-87], or hearing impairment (highly probably irreversible) [88]. Precautions to avoid tumor lysis syndrome include initial administration of fluid (dose $2 \mathrm{~L} / \mathrm{sqm}$ body surface). $\mathrm{NaHCO}_{3}$ may be used to adjust urine $\mathrm{pH}$ within a range of $\mathrm{pH} 6.4$ to $\mathrm{pH} 6.8$ to optimize excretion of uric acid and addition of allopurinol in those cases with elevated uric acid serum levels.

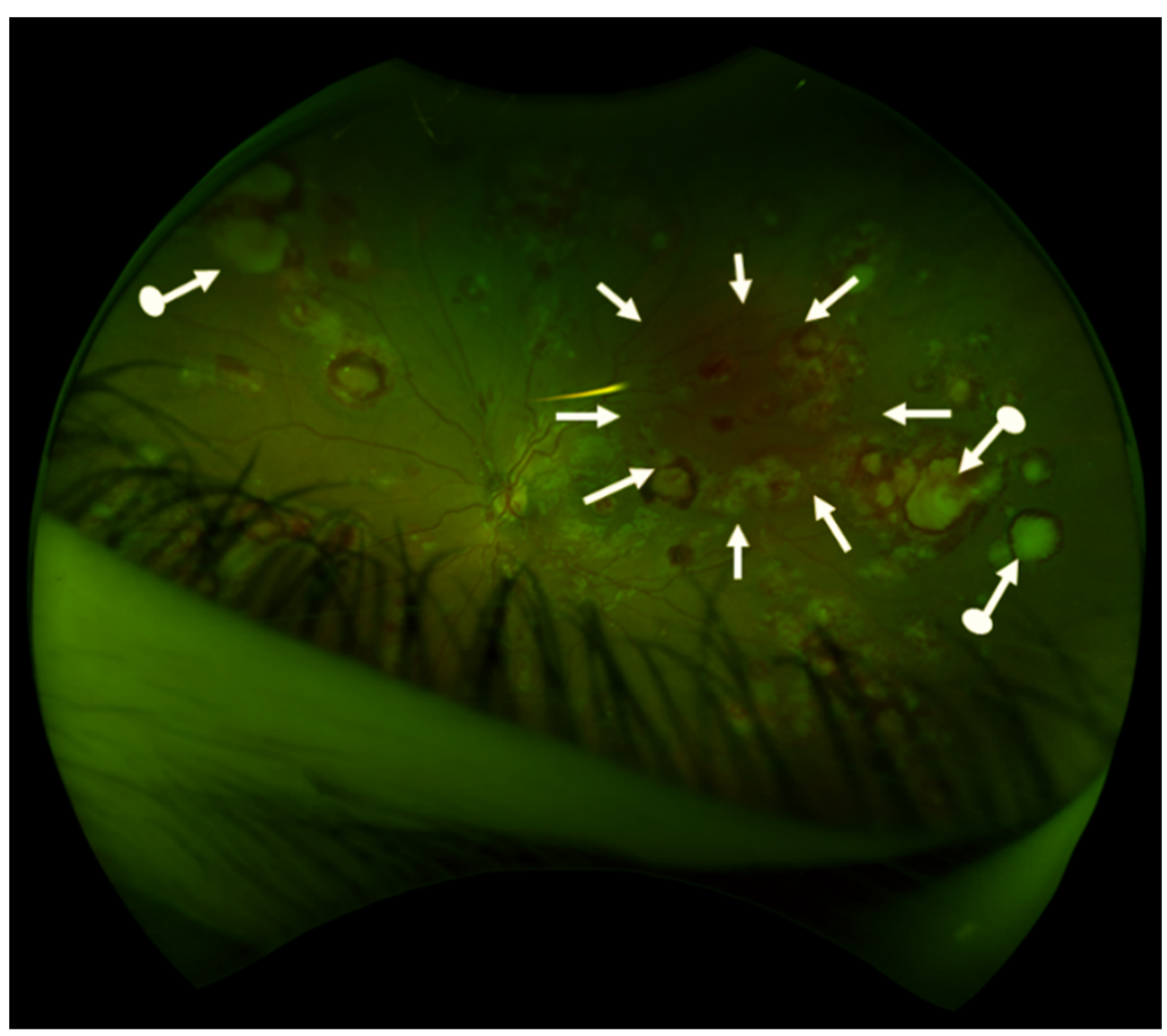

Figure 4. Retinal findings in a 15-year old girl who presented with blurred vision, massive splenomegaly and leukocytosis. A diagnosis of CML-AP was made. Retina is the most commonly involved intraocular structure in CML. Fundus showed retinal hemorrhages in both eyes (white arrows) and multiple white centered infiltrates "cotton-wool spots" (arrows with dot, not all infiltrates are marked). Photography (OPTOS retinal camera) by courtesy of F. Gekeler, Stuttgart).

Splenomegaly is observed in two thirds of all pediatric patients. Imaging procedures show no grossly visible nodules; however, splenic infarcts may appear if the organ is massively enlarged (Figure 5). Rarely, cases with splenic rupture have been reported in adults, but so far, not in children [89]. 


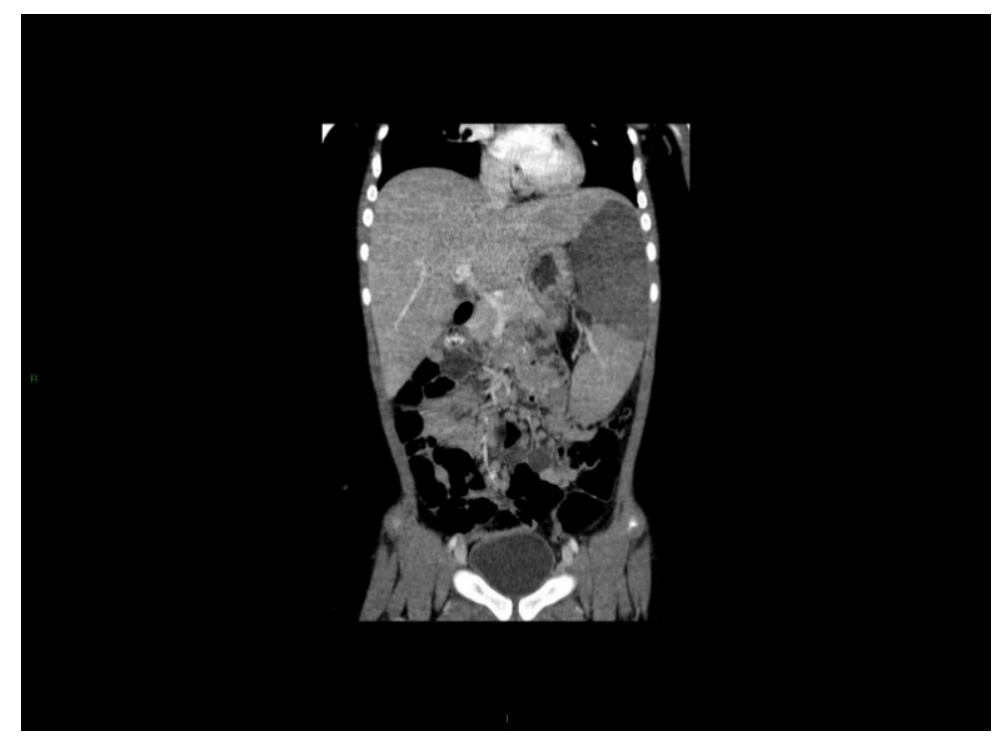

Figure 5. Splenic infarction at diagnosis of CML. A seven years-old girl presented with abdominal pain, splenomegaly and massive leukocytosis. Coronal CT after contrast injection showed an enlarged spleen with a large central hypodensity, well limited, with low enhancement and rectilinear borderlines. Photography by courtesy of Prof. Arnaud Y. Petit, Paris, France. For details and outcome see reference [90].

\section{Histopathological Findings}

Comparable to CML in adults, the marrow in pediatric CML-CP is significantly hypercellular $(95 \%-100 \%)$ presenting with markedly increased granulopoieses and a virtual absence of adipocytes (Figure 6). The ratio myeloid to erythroid cells is $\geq 10: 1$ with usually an impressively predominant proportion of myelocytes, promyelocytes and segmented neutrophils; the ratio of myeloblasts in CML-CP by definition may be up to $10 \%$. Mega-karyocytic proliferation is present in $>50 \%$ of the cases with micromegakaryocytes (hypolobated nuclei) (Figure 6). Typically, these findings are accompanied by immature eosinophils and basophils [91] (Figure 7). Eosinophils with atypical basophilic staining granules known as a "Harlequin" cell are also most commonly seen in CML [92]. Pseudo Gaucher cells and see-blue histiocytes can be found inhomogenously distributed in the marrow aspirate smears (Figure 8) in approximately one third of pediatric patients [93]. Grades of fibrosis are varying and manifest myelofibrosis has been described as an adverse morphological factor in adult CML which may be detected in 15\% of pediatric CML [94].
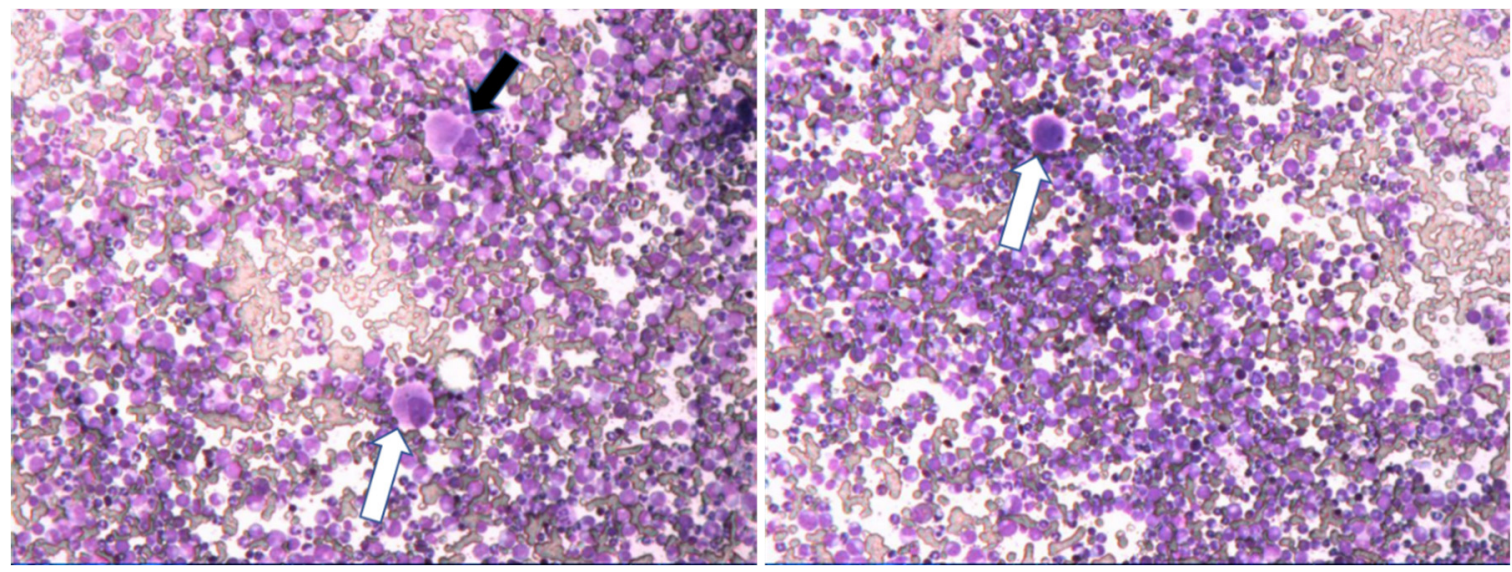

Figure 6. Significant hypercellular marrow at diagnosis of CML-CP showing also small hypolobulated megakaryocytes (black arrow) and micromegakaryocytes (white arrows). Magnification $80 \times$. 


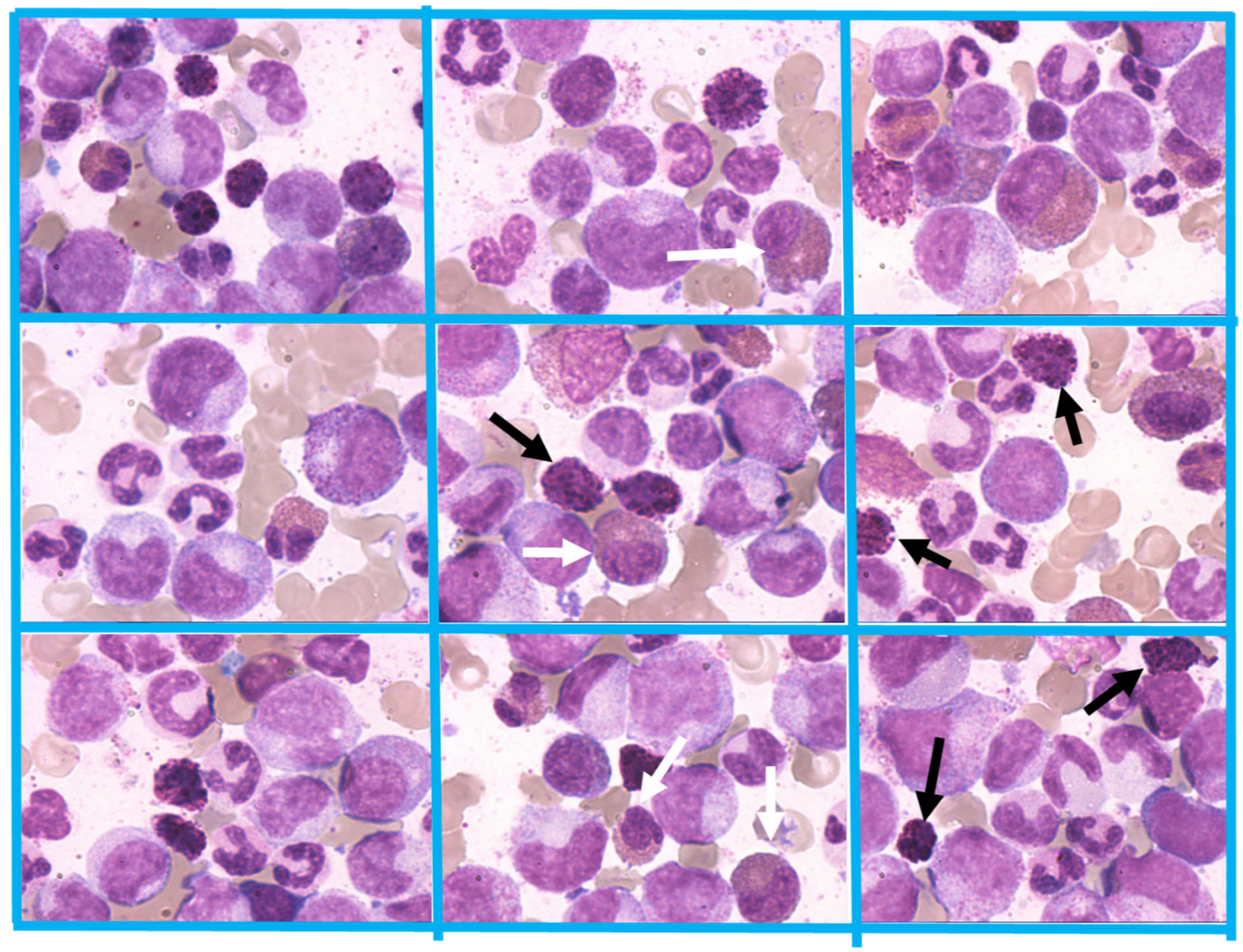

Figure 7. CML-CP presenting with characteristic hyperplasia of the granulocytic lineage with increased number of precursor cells (left-shifted granulopoiesis). In addition, typical immature basophils (black arrows) and immature eosinophils (white arrows) are present. Magnification $800 \times$.

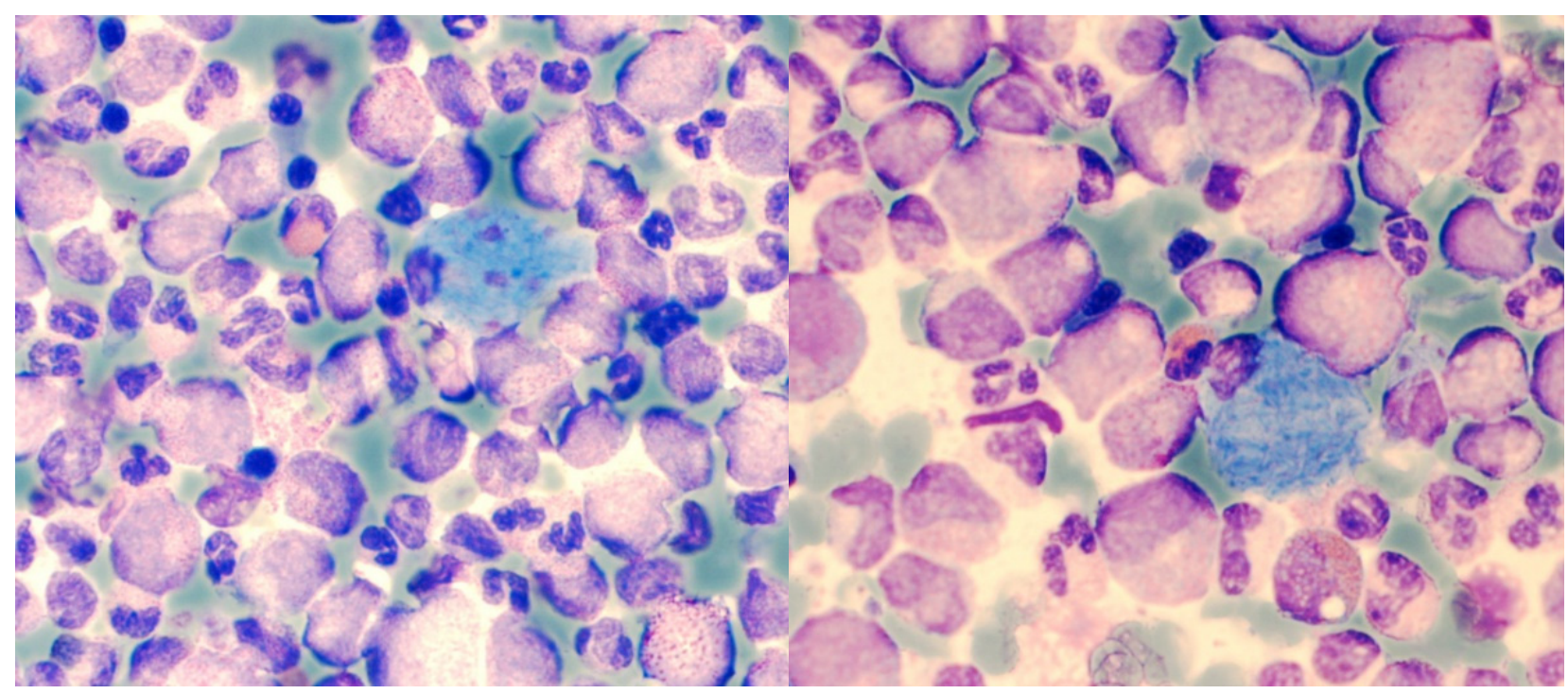

(a) (b)

Figure 8. Bone marrow smears showing deep-blue Pseudo Gaucher cells. Magnification $800 \times$. 
By definition in CML-AP myeloblasts make up 10\% -19\% of marrow nucleated cells. Often massive basophilia (>20\% basophils) is found. An increased number of megakaryocytes is organized in clusters with expressive fibrosis detectable. CML-BP is indistinguishable from acute leukemia representing either myeloblasts (AML) or lymphoblasts (ALL). Sometimes transformation into acute myelomonocytic leukemia or rarely into biphenotypic/bilinear leukemia is diagnosed.

\section{Cytology/Immunophenotype}

The leukocyte (neutrophil) alkaline phosphatase (LAP) level as a marker of terminally differentiated neutrophilic granulocytes is decreased in CML $[95,96]$. Antigens normally found on neutrophils (CD15, HLA-DR) may be expressed weakly. However, cytochemistry is no longer important in the diagnosis of CML as cytogenetic and molecular genetic analysis permit a much more precise diagnosis. In routine diagnostics, immunophenotyping has no useful role during CML-CP. However, in CML-BP blasts of lymphoid lineage -either upfront at diagnosis of CML or during treatment developing under imatinib-are found more frequently than in adults [97]. Notably, CML-BP-lymphoid is associated with a better prognosis than CML-BP-myeloid [74,78].

CML-BP-lymphoid is usually of B-lineage expressing precursor B lymphoblastic antigens (CD10+, CD19+, CD34+, TdT+, sIg-), but cases of precursor T-cell origin (CD3+, CD7+, TdT+) have been described, too $[97,98]$. The co-expression of myeloid antigens on lymphoid blasts is frequent (Figure 9). In CML-BP-myeloid myeloperoxidase may be expressed variably (missing, weak, strong), but will show antigens associated with myeloid, monocytic, megakaryocytic, and/or erythroid differentiation. Not uncommonly, one or more lymphoid antigens are also expressed. Rarely, CML-BP blasts of lymphoid and myeloid lineage are present simultaneously [99].

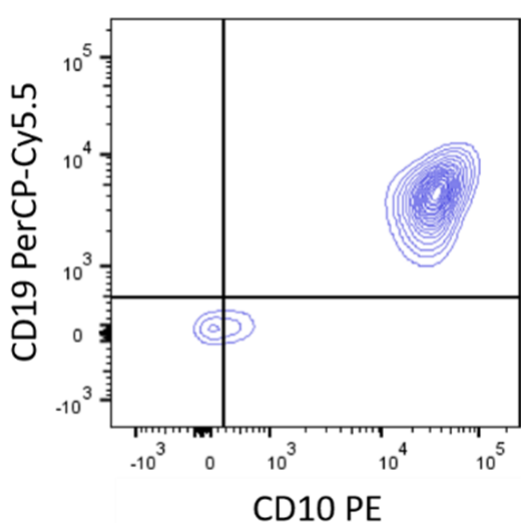

(a)

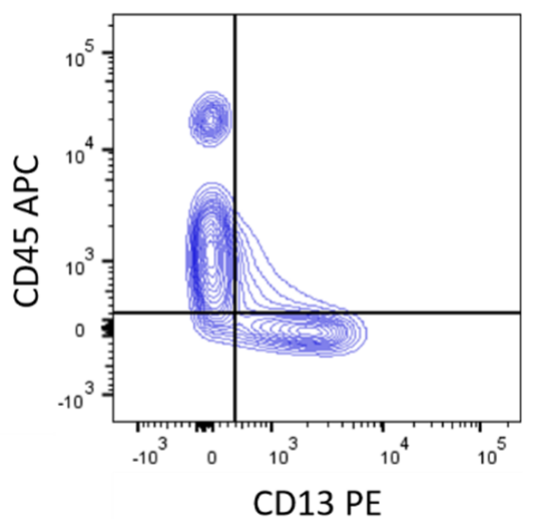

(b)

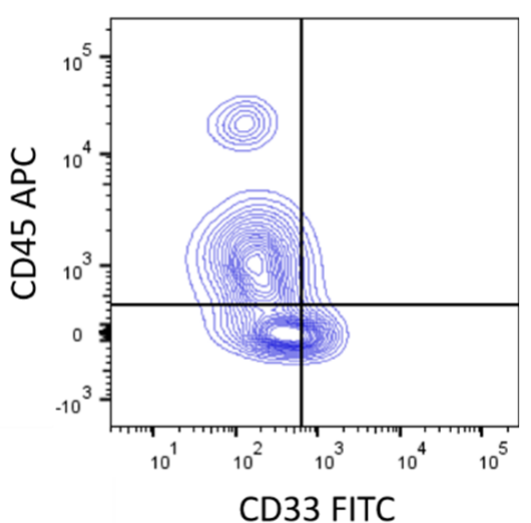

(c)

Figure 9. FACS analysis of CML-BP-lymphoid (CD10, CD19) with co-expression of myeloid (CD13, CD33) markers.

\section{Diagnostic Assessments}

Morphology and cytogenetics from a bone marrow aspirate still form the absolutely essential basis of diagnosis [19,20,100,101]. Determining the proportion of blast cells by morphology will assess the correct stage (CML-CP, -AP, -BP), while cytogenetics by complete banding assay of Giemsa-stained metaphases cells identifies the Ph1 chromosome. Karyotyping is also important to rule out additional chromosomal aberrations serving as a warning sign of a poorer prognosis [14,19]. A trephine biopsy should be done in addition to evaluate the degree of fibrosis and may identify nests of blasts, not evident in the aspirate, which both have prognostic impact [94,102-104]. If a molecular assay 
(see below) demonstrates BCR-ABL1, but the Ph1 chromosome cannot be identified by cytogenetics, a FISH test is required.

At diagnosis, performing a reverse transcriptase PCR (RT-PCR) assay on peripheral blood cells is mandatory to identify the type of BCR-ABL1 transcript as a marker for molecular monitoring in response to TKI-treatment [105]. Up to $5 \%$ of patients may harbor atypical BCR-ABL1 transcripts lacking ABL1 exon2 or resulting from atypical BCR breakpoints (see Section 5) [27]. Using routine primer/probe sets may yield a false negative PCR in qualitative or quantitative RT-PCR protocols thus hampering the subsequent assessment of molecular response [106,107].

\section{Essential and Desirable Diagnostic Criteria}

The following criteria are essential to diagnose CML BCR-ABL1:

- $\quad$ Full blood count with manual differential for percent of blasts, promyelocytes, eosinophils, and basophils. It should be performed before any therapy has been given and is useful to assess the correct stage of the disease and to calculate prognostic risk scores

- $\quad$ spleen size, liver size (both in $\mathrm{cm}$ below the costal margin) on quiet breathing,

- assessment of extramedullary manifestation of CML (lymph nodes, skin, bone, etc.),

- demonstration of the $\mathrm{Ph}+$ chromosome, including assessment of additional chromosomal aberrations, loss of chromosomes, derivative chromosome 9,

- demonstration of the BCR-ABL1 fusion gene,

- $\quad$ type of fusion gene transcript type as detected by RT-PCR

Assessment of the following criteria is desirable when CML BCR-ABL1 is diagnosed:

- (a) for optimal monitoring of treatment response in individual patients:

- gender, age, height, bodyweight in correlation to the TKI dose administered [108],

- identification of mutations in the BCR-ABL1 kinase domain in patients with CML-AP and CML-BP,

- identification of the BCR-ABL1 breakpoint on a genomic (DNA) level [63,66,109-112],

- (b) to compare data on pediatric CML BCR-ABL1 internationally:

- a threphine biopsy (degree of fibrosis, nests of blasts),

- due to the rarity of pediatric CML all patients should be enrolled in trials and enrolled into the international pediatric CML registry [4],

- for comparison of BCR-ABL1 mRNA levels when assessing the treatment response, data derived from individual laboratories must be aligned to a reference method (International Standard, IS) applying laboratory-specific conversion factors [113,114],

- (c) to improve the scientific understanding of the disease:

- identification of genes and their products influencing TKI blood serum concentration and metabolism [108,115],

- $\quad$ assessment of acquired von Willebrand disease in cases with elevated platelets [73,81],

- vaccination status at diagnosis and maintenance of immunity under TKI treatment [116-118],

- identification of somatic or germline mutations and epigenetic modification in addition to BCR-ABL1 [55,57,66,112,119-122].

\section{Prognosis and Prediction}

The prognosis of adult patients with CML could be predicted with prognostic scores (e.g., Sokal, Hasford, EUTOS) based on the clinical and biological characteristics of the disease at diagnosis $[120,123]$. The usefulness of these scores has not been formally demonstrated in children. However, the EUTOS Long Term Survival (ELTS) score showed better differentiation in terms of progression free survival than other scores in children with CML and could be incorporated into therapeutic strategy for childhood CML [72]. Moreover, kinetics of decreasing transcript levels within the first months of treatment could identify children requiring an alternative treatment strategy [124]. 
As can be depicted from Figure 1 (see above, Section 5), due to the additional exon e14, the mRNA chain of transcript e14a2 is longer than of transcript e13a2. The length of the corresponding translated protein p210e14a2 differs by 25 amino acid residues coded by the e14 exon and an amino acid substitution (Glu903Asp) [24]. Several studies analyzed in adult patients with CML whether the two transcripts e14a2 and e13a2 have different responses to imatinib treatment (for an overview see $[125,126]$ ). According to the majoritybut not all-studies published, patients with e13a2 transcript treated with imatinib have lower and slower cytogenetic and molecular responses than those with an e14a2 transcript. In pediatric cohorts with CML the frequency of the two transcript types has been analyzed showing a slightly higher incidence of e14a2 than in adults. However, the prognostic relevance and significance of either transcript type for therapy or long-term survival have not been clearly defined due to the rarity of the disease [70,127].

\section{Summary and Conclusions}

The rarity of CML in pediatrics results in little experience even in physicians involved for prolonged periods in the treatment of childhood cancers. This article, as the first part of a series on pediatric CML, aims to provide precise definitions and to unify the terminology in relation to the WHO ICD codes and the methods applied for diagnosis of pediatric CML. The Ph1 chromosome and the resulting BCR-ABL1 rearrangement are the hallmarks of this leukemia and thus this entity is separated sharply from other differential diagnoses. As in adults, pediatric CML is classified by the phase of the disease and subtypes can be defined by distinct BCR-ABL1 rearrangements. The identification of the resulting different $m$-RNA fusion transcripts forms the basis for quantification of residual disease when monitoring the treatment response.

Pediatric CML presents at diagnosis with biological features different from adult CML pointing towards a more aggressive course of the disease. However, histopathological, cytogenetic, and immunophenotype analyses are comparable to findings in adults. At diagnosis of CML treating physicians must be alert of rarely occurring but typical clinical complications resulting from rheological problems. Finally, essential and desirable diagnostic criteria are listed which hopefully will help to unify the attempts when approaching this rare pediatric malignancy. Evidently only a clear picture of all relevant features can lay the basis for standardized treatment approaches.

Author Contributions: All authors developed the concept of this typoscript. M.S., M.M., and F.M. treated individual patients and communicated in their role as study chair with treatment centers enrolling patients into ongoing trials on pediatric CML. F.M. assured data collection and management of the international registry of pediatric CML. S.S. and H.D. performed detailed data analysis and provided tables and figures. M.S. wrote the first draft of the typoscript and all authors critically discussed the content. All authors have read and agreed to the published version of the manuscript.

Funding: This research received no external funding.

Institutional Review Board Statement: Not applicable for this review.

Informed Consent Statement: Informed consent was obtained from all subjects and their legal guardians treated because of CML whose diagnostic features are shown as photos in this review.

Data Availability Statement: Not applicable for this review.

Conflicts of Interest: The authors declare no conflict of interest.

Disclosures: M.S. and M.M. have received honoraria for consulting and lectures from Novartis Pharma and Bristol Myers Sqibb Pharma as well as research grants (institutional) from Novartis Pharma. F.M., H.D., and S.S. have nothing to disclose. 


\section{References}

1. Champagne, M.A.; Capdeville, R.; Krailo, M.; Qu, W.; Peng, B.; Rosamilia, M.; Therrien, M.; Zoellner, U.; Blaney, S.M.; Bernstein, M.; et al. Imatinib mesylate (STI571) for treatment of children with Philadelphia chromosome-positive leukemia: Results from a Children's Oncology Group phase 1 study. Blood 2004, 104, 2655-2660. [CrossRef] [PubMed]

2. Cwynarski, K.; Roberts, I.A.; Iacobelli, S.; van Biezen, A.; Brand, R.; Devergie, A.; Vossen, J.M.; Aljurf, M.; Arcese, W.; Locatelli, F.; et al. Stem cell transplantation for chronic myeloid leukemia in children. Blood 2003, 102, $1224-1231$. [CrossRef] [PubMed]

3. Suttorp, M. Innovative approaches of targeted therapy for CML of childhood in combination with paediatric haematopoietic SCT. Bone Marrow Transplant. 2008, 42 (Suppl. S2), S40-S46. [CrossRef]

4. Suttorp, M.; Metzler, M.; Millot, F. Horn of plenty: Value of the international registry for pediatric chronic myeloid leukemia. World J. Clin Oncol. 2020, 11, 308-319. [CrossRef] [PubMed]

5. Hasle, H. Myelodysplastic and myeloproliferative disorders of childhood. Hematol. Am. Soc. Hematol. Educ. Program. 2016, 2016, 598-604. [CrossRef]

6. Nitta, M.; Kato, Y.; Strife, A.; Wachter, M.; Fried, J.; Perez, A.; Jhanwar, S.; Duigou-Osterndorf, R.; Chaganti, R.S.; Clarkson, B. Incidence of Involvement of the B and T Lymphocyte Lineages in Chronic Myelogenous Leukemia. Blood 1985, 66, 1053-1061. [CrossRef]

7. Nogueira-Costa, R.; Spitzer, G.; Khorana, S.; Pham, Q.; Kantarjian, H.M.; Manning, J.T.; Ordonez, N.G.; Dicke, K.A. T-cell Involvement in Benign Phase Chronic Myelogenous Leukemia. Leuk Res. 1986, 10, 1433-1439. [CrossRef]

8. Fang, B.; Zheng, C.; Liao, L.; Han, Q.; Sun, Z.; Jiang, X.; Zhao, R.C. Identification of human chronic myelogenous leukemia progenitor cells with hemangioblastic characteristics. Blood 2005, 105, 2733-2740. [CrossRef]

9. Gunsilius, E.; Duba, H.C.; Petzer, A.L.; Kahler, C.M.; Grunewald, K.; Stockhammer, G.; Gabl, C.; Dirnhofer, S.; Clausen, J.; Gastl, G. Evidence from a leukaemia model for maintenance of vascular endothelium by bone-marrow-derived endothelial cells. Lancet 2000, 355, 1688-1691. [CrossRef]

10. Otten, J.; Schultze, A.; Schafhausen, P.; Otterstetter, S.; Dierlamm, J.; Bokemeyer, C.; Brummendorf, T.H.; Fiedler, W.; Loges, S. Blood outgrowth endothelial cells from chronic myeloid leukaemia patients are BCR/ABL1 negative. Br. J. Haematol. 2008, 142, 115-118. [CrossRef] [PubMed]

11. Niemeyer, C.M. JMML genomics and decisions. Hematol. Am. Soc. Hematol. Educ. Program. 2018, $2018,307-312$. [CrossRef] [PubMed]

12. Chang, T.Y.; Dvorak, C.C.; Loh, M.L. Bedside to bench in juvenile myelomonocytic leukemia: Insights into leukemogenesis from a rare pediatric leukemia. Blood 2014, 124, 2487-2497. [CrossRef] [PubMed]

13. Locatelli, F.; Niemeyer, C.M. How I treat juvenile myelomonocytic leukemia. Blood 2015, 125, 1083-1090. [CrossRef]

14. Millot, F.; Dupraz, C.; Guilhot, J.; Suttorp, M.; Brizard, F.; Leblanc, T.; Güneş, A.M.; Sedlacek, P.; De Bont, E.; Li, C.K.; et al. Additional cytogenetic abnormalities and variant $\mathrm{t}(9 ; 22)$ at the diagnosis of childhood chronic myeloid leukemia: The experience of the International Registry for Chronic Myeloid Leukemia in Children and Adolescents. Cancer 2017, 123, 3609-3616. [CrossRef] [PubMed]

15. Arber, D.A.; Orazi, A.; Hasserjian, R.; Thiele, J.; Borowitz, M.J.; Le Beau, M.M.; Bloomfield, C.D.; Cazzola, M.; Vardiman, J.W. The 2016 revision to the World Health Organization classification of myeloid neoplasms and acute leukemia. Blood 2016, 127, 2391-2405. [CrossRef]

16. Vardiman, J.W.; Pierre, R.; Thiele, J.; Imbert, M.; Brunning, R.D.; Flandrin, G. Chronic myelogenous leukaemia. In World Health Organization Classification of Tumours: Pathology and Genetics-Tumours of Haematopoietic and Lymphoid Tissues; Jaffe, E.S., Harris, N.L., Stein, H., Vardiman, J.W., Eds.; IARC Press: Lyon, France, 2016; pp. 20-26.

17. Baccarani, M.; Saglio, G.; Goldman, J.; Hochhaus, A.; Simonsson, B.; Appelbaum, F.; Apperley, J.; Cervantes, F.; Cortes, J.; Deininger, M.; et al. Evolving concepts in the management of chronic myeloid leukemia: Recommendations from an expert panel on behalf of the European LeukemiaNet. Blood 2006, 108, 1809-1820. [CrossRef]

18. Cortes, J.E.; Talpaz, M.; O’Brien, S.; Faderl, S.; Garcia-Manero, G.; Ferrajoli, A.; Verstovsek, S.; Rios, M.B.; Shan, J.; Kantarjian, H.M. Staging of chronic myeloid leukemia in the imatinib era: An evaluation of the World Health Organization proposal. Cancer 2006, 106, 1306-1315. [CrossRef]

19. De la Fuente, J.; Baruchel, A.; Biondi, A.; de Bont, E.; Dresse, M.F.; Suttorp, M.; Millot, F.; International BFM Group (iBFM) Study Group Chronic Myeloid Leukaemia Committee. Managing children with chronic myeloid leukaemia (CML): Recommendations for the management of CML in children and young people up to the age of 18 years. Br. J. Haematol. 2014, 167, 33-47. [CrossRef]

20. Athale, U.; Hijiya, N.; Patterson, B.C.; Bergsagel, J.; Andolina, J.R.; Bittencourt, H.; Schultz, K.R.; Burke, M.J.; Redell, M.S.; Kolb, E.A.; et al. Management of chronic myeloid leukemia in children and adolescents: Recommendations from the Children's Oncology Group CML Working Group. Pediatr. Blood Cancer 2019, 66, e27827. [CrossRef]

21. NCCN Guidelines Version 2.Chronic Myeloid Leukemia. Available online: www.nccn.org/professionals/physician_gls/pdf/cml. pdf (accessed on 3 December 2020).

22. Adler, R.; Viehmann, S.; Kuhlisch, E.; Martiniak, Y.; Röttgers, S.; Harbott, J.; Suttorp, M. Correlation of BCR/ABL transcript variants with patients' characteristics in childhood chronic myeloid leukaemia. Eur. J. Haematol. 2009, 82, 112-118. [CrossRef] 
23. Mughal, T.I.; Radich, J.P.; Deininger, M.W.; Apperley, J.F.; Hughes, T.P.; Harrison, C.J.; Gambacorti-Passerini, C.; Saglio, G.; Cortes, J.; Daley, G.Q. Chronic myeloid leukemia: Reminiscences and dreams. Haematologica 2016, 101, 541-558. [CrossRef] [PubMed]

24. Quintás-Cardama, A.; Cortes, J. Molecular biology of bcr-abl1-positive chronic myeloid leukemia. Blood 2009, 113, 1619-1630. [CrossRef] [PubMed]

25. Barnes, D.J.; Melo, J.V. Cytogenetic and molecular genetic aspects of chronic myeloid leukaemia. Acta Haematol. 2002, 108, 180-202. [CrossRef] [PubMed]

26. Melo, J.V. The diversity of BCR-ABL fusion proteins and their relationship to leukemia phenotype. Blood 1996, 88, 2375-2384. [CrossRef]

27. Baccarani, M.; Castagnetti, F.; Gugliotta, G.; Rosti, G.; Soverini, S.; Albeer, A.; Pfirrmann, M.; International BCR-ABL Study Group. The proportion of different BCR-ABL1 transcript types in chronic myeloid leukemia. An international overview. Leukemia 2019, 33, 1173-1183. [CrossRef]

28. Demehri, S.; Paschka, P.; Schultheis, B.; Lange, T.; Koizumi, T.; Sugimoto, T.; Branford, S.; Lim, L.C.; Kegel, T.; Martinelli, G.; et al. e8aBCR-ABL: More frequent than other atypical BCR-ABL variants? Leukemia 2005, 19, 681-684. [CrossRef]

29. Hochhaus, A.; Reiter, A.; Skladny, H.; Melo, J.V.; Sick, C.; Berger, U.; Guo, J.Q.; Arlinghaus, R.B.; Hehlmann, R.; Goldman, J.M.; et al. A novel BCR-ABL fusion gene (e6a2) in a patient with Philadelphia chromosome-negative chronic myelogenous leukemia. Blood 1996, 88, 2236-2240. [CrossRef]

30. Van der Velden, V.H.; Beverloo, H.B.; Hoogeveen, P.G.; Zwaan Ch, M. A novel BCR-ABL fusion transcript (e18a2) in a child with chronic myeloid leukemia. Leukemia 2007, 21, 833-835. [CrossRef] [PubMed]

31. Mandal, P.; Mukherjee, S.B. Leukemoid Reaction-A Tale of Years. Indian Pediatr. 2015, 52, 973-974. [CrossRef]

32. Sakka, V.; Tsiodras, S.; Giamarellos-Bourboulis, E.J.; Giamarellou, H. An update on the etiology and diagnostic evaluation of a leukemoid reaction. Eur. J. Intern. Med. 2006, 17, 394-398. [CrossRef]

33. Hoofien, A.; Yarden-Bilavski, H.; Ashkenazi, S.; Chodick, G.; Livni, G. Leukemoid reaction in the pediatric population: Etiologies, outcome, and implications. Eur. J. Pediatr. 2018, 177, 1029-1036. [CrossRef]

34. Karow, A.; Nienhold, R.; Lundberg, P.; Peroni, E.; Putti, M.C.; Randi, M.L.; Skoda, R.C. Mutational profile of childhood myeloproliferative neoplasms. Leukemia 2015, 29, 2407-2409. [CrossRef]

35. Sekhar, M.; Prentice, H.G.; Popat, U.; Anderson, D.; Janmohammed, R.; Roberts, I.; Britt, R.P. Idiopathic myelofibrosis in children. Br. J. Haematol. 1996, 93, 394-397. [CrossRef]

36. Ding, N.; Zhang, Z.; Yang, W.; Ren, L.; Zhang, Y.; Zhang, J.; Li, Z.; Zhang, P.; Zhu, X.; Chen, X.; et al. Transcriptome Analysis of Monozygotic Twin Brothers with Childhood Primary Myelofibrosis. Genom. Proteom. Bioinform. 2017, 15, 37-48. [CrossRef] [PubMed]

37. Mitton, B.; de Oliveira, S.; Pullarkat, S.T.; Moore, T.B. Stem cell transplantation in primary myelofibrosis of childhood. J. Pediatr. Hematol. Oncol. 2013, 35, e120-e122. [CrossRef] [PubMed]

38. Kratz, C.P.; Franke, L.; Peters, H.; Kohlschmidt, N.; Kazmierczak, B.; Finckh, U.; Bier, A.; Eichhorn, B.; Blank, C.; Kraus, C.; et al. Cancer spectrum and frequency among children with Noonan, Costello, and cardio-facio-cutaneous syndromes. Br. J. Cancer 2015, 112, 1392-1397. [CrossRef] [PubMed]

39. Swerdlow, S.H.; Campo, E.; Harris, N.L.; Jaffe, E.S.; Pileri, S.A.; Stein, H.; Thiele, J.; Arber, D.A.; Hasserjian, R.P.; Le Beau, M.M.; et al. (Eds.) WHO Classification of Tumours of Haematopoietic and Lymphoid Tissues; IARC Press: Lyon, France, 2017.

40. Malhotra, H.; Radich, J.; Garcia-Gonzalez, P. Meeting the Needs of CML Patients in Resource-Poor Countries. Hematol. Am. Soc. Hematol. Educ. Program 2019, 2019, 433-442. [CrossRef] [PubMed]

41. National Cancer Institute. Cancer Stat Facts: Leukemia-Chronic Myeloid Leukemia (CML). 2018. Available online: https: / / seer.cancer.gov / statfacts/html/cmyl.html. (accessed on 3 December 2020).

42. Wang, A.; Wang, Y.; Yao, Y.; Xu, Z.; Zhou, L.; Wang, L.; Zhang, L.; Chen, Y.; Shen, Z.; Hu, J.; et al. Summary of 615 patients of chronic myeloid leukemia in Shanghai from 2001 to 2006. J. Exp. Clin. Cancer Res. 2010, 29, 20. [CrossRef] [PubMed]

43. Tanizawa, A. Optimal management for pediatric CML. Pediatrics Int. 2016, 58, 171-179. [CrossRef]

44. Meral Günes, A.; Millot, F.; Kalwak, K.; Lausen, B.; Sedlacek, P.; de Bruijn, C.A.M.; Dworzak, M.; de Moerloose, B.; Suttorp, M. Features and Outcome of Chronic Myeloid Leukemia at Very Young Age - Data from the International Pediatric CML Registry (I-CML-Ped Study). Ped Blood Cancer 2021, 68, e28706. [CrossRef]

45. Available online: https://seer.cancer.gov/archive/csr/1975_2015/results_merged/sect_29_childhood_cancer_iccc.pdf (accessed on 1 August 2020).

46. Alsop, S.; Sanger, W.G.; Elenitoba-Johnson, K.S.; Lim, M.S. Chronic myeloid leukemia as a secondary malignancy after ALKpositive anaplastic large cell lymphoma. Hum Pathol. 2007, 38, 1576-1580. [CrossRef] [PubMed]

47. Bauduer, F.; Ducout, L.; Dastugue, N.; Marolleau, J.P. Chronic myeloid leukemia as a secondary neoplasm after anticancer radiotherapy: A report of three cases and a brief review of the literature. Leuk Lymphoma 2002, 43, 1057-1060. [CrossRef] [PubMed]

48. Millett, R.; Aggarwal, A.; Tabbara, I.; Nassereddine, S. Chronic Myeloid Leukemia as Secondary Malignancy Following the Treatment of Hodgkin Lymphoma: A Case Series. Anticancer Res. 2019, 39, 4333-4335. [CrossRef] [PubMed] 
49. Zahra, K.; Ben Fredj, W.; Ben Youssef, Y.; Zaghouani, H.; Chebchoub, I.; Zaier, M.; Badreddine, S.; Braham, N.; Sennana, H.; Khelif, A. Chronic myeloid leukemia as a secondary malignancy after lymphoma in a child. A case report and review of the literature. Onkologie 2012, 35, 690-693. [CrossRef] [PubMed]

50. Bizzozero, O.J., Jr.; Johnson, K.G.; Ciocco, A. Radiation-related leukemia in Hiroshima and Nagasaki, 1946-I. Distribution, incidence and appearance time. N. Engl. J. Med. 1966, 274, 1095-1101. [CrossRef] [PubMed]

51. Corso, A.; Lazzarino, M.; Morra, E.; Merante, S.; Astori, C.; Bernasconi, P.; Boni, M.; Bernasconi, C. Chronic myelogenous leukemia and exposure to ionizing radiation-a retrospective study of 443 patients. Ann. Hematol. 1995, 70, 79-82. [CrossRef]

52. Finch, S.C.; Linet, M.S. Chronic Leukaemias. Baillieres Clin Haematol. 1992, 5, 27-56. [CrossRef]

53. Radivoyevitch, T.; Jankovic, G.M.; Tiu, R.V.; Saunthararajah, Y.; Jackson, R.C.; Hlatky, L.R.; Gale, R.P.; Sachs, R.K. Sex differences in the incidence of chronic myeloid leukemia. Radiat. Environ. Biophys. 2014, 53, 55-63. [CrossRef]

54. Ernst, T.; Busch, M.; Rinke, J.; Ernst, J.; Haferlach, C.; Beck, J.F.; Hochhaus, A.; Gruhn, B. Frequent ASXL1 mutations in children and young adults with chronic myeloid leukemia. Leukemia 2018, 32, 2046-2049. [CrossRef]

55. Togasaki, E.; Takeda, J.; Yoshida, K.; Shiozawa, Y.; Takeuchi, M.; Oshima, M.; Saraya, A.; Iwama, A.; Yokote, K.; Sakaida, E.; et al. Frequent somatic mutations in epigenetic regulators in newly diagnosed chronic myeloid leukemia. Blood Cancer J. 2017, 7, e559. [CrossRef]

56. Deininger, M.W.; Goldman, J.M.; Melo, J.V. The molecular biology of chronic myeloid leukemia. Blood 2000, 96, 3343-3356. [CrossRef]

57. Branford, S.; Wang, P.; Yeung, D.T.; Thomson, D.; Purins, A.; Wadham, C.; Shahrin, N.H.; Marum, J.E.; Nataren, N.; Parker, W.T.; et al. Integrative genomic analysis reveals cancer-associated mutations at diagnosis of CML in patients with high-risk disease. Blood 2018, 132, 948-961. [CrossRef]

58. Shanmuganathan, N.; Branford, S. The Hidden Pathogenesis of CML: Is BCR-ABL1 the First Event? Curr. Hematol. Malig. Rep. 2019, 14, 501-506. [CrossRef] [PubMed]

59. Krumbholz, M.; Karl, M.; Tauer, J.T.; Thiede, C.; Rascher, W.; Suttorp, M.; Metzler, M. Genomic BCR-ABL1 breakpoints in pediatric chronic myeloid leukemia. Genes Chromosomes Cancer 2012, 51, 1045-1053. [CrossRef]

60. Greaves, M.F.; Maia, A.T.; Wiemels, J.L.; Ford, A.M. Leukemia in twins: Lessons in natural history. Blood. 2003, 102, $2321-2333$. [CrossRef] [PubMed]

61. Greaves, M. A causal mechanism for childhood acute lymphoblastic leukaemia. Nat. Rev. Cancer 2018, 18, 471-484. [CrossRef]

62. Abecasis, M.; Cross, N.C.P.; Brito, M.; Ferreira, I.; Sakamoto, K.M.; Hijiya, N.; Score, J.; Gale, R.P. Is cancer latency an outdated concept? Lessons from chronic myeloid leukemia. Leukemia 2020, 34, 2279-2284. [CrossRef]

63. Krumbholz, M.; Goerlitz, K.; Albert, C.; Lawlor, J.; Suttorp, M.; Metzler, M. Large amplicon droplet digital PCR for DNA-based monitoring of pediatric chronic myeloid leukaemia. J. Cell Mol. Med. 2019, 23, 4955-4961. [CrossRef]

64. Score, J.; Calasanz, M.J.; Ottman, O.; Pane, F.; Yeh, R.F.; Sobrinho-Simões, M.A.; Kreil, S.; Ward, D.; Hidalgo-Curtis, C.; Melo, J.V.; et al. Analysis of genomic breakpoints in p190 and pBCR-ABL indicate distinct mechanisms of formation. Leukemia 2010, 24, 1742-1750. [CrossRef]

65. Kuan, J.W.; Su, A.T.; Leong, C.F.; Osato, M.; Sashida, G. Systematic Review of Normal Subjects Harbouring BCR-ABLFusion Gene. Acta Haematol. 2020, 143, 96-111. [CrossRef] [PubMed]

66. Branford, S.; Kim, D.D.H.; Apperley, J.F.; Eide, C.A.; Mustjoki, S.; Ong, S.T.; Nteliopoulos, G.; Ernst, T.; Chuah, C.; Gambacorti-Passerini, C.; et al. Laying the foundation for genomically-based risk assessment in chronic myeloid leukemia. Leukemia 2019, 33, 1835-1850. [CrossRef]

67. Holyoake, T.L.; Vetrie, D. The chronic myeloid leukemia stem cell: Stemming the tide of persistence. Blood 2017, 129, 1160-1595. [CrossRef]

68. Perrotti, D.; Silvestri, G.; Stramucci, L.; Yu, J.; Trotta, R. Cellular and Molecular Networks in Chronic Myeloid Leukemia: The Leukemic Stem, Progenitor and Stromal Cell Interplay. Curr. Drug Targets 2017, 18, 377-388. [CrossRef] [PubMed]

69. Millot, F.; Traore, P.; Guilhot, J.; Nelken, B.; Leblanc, T.; Leverger, G.; Plantaz, D.; Bertrand, Y.; Bordigoni, P.; Guilhot, F. Clinical and biological features at diagnosis in 40 children with chronic myeloid leukemia. Pediatrics 2005, 116, 140-143. [CrossRef] [PubMed]

70. Suttorp, M.; Schulze, P.; Glauche, I.; Göhring, G.; von Neuhoff, N.; Metzler, M.; Sedlacek, P.; de Bont, E.S.J.M.; Balduzzi, A.; Lausen, B.; et al. Front-line imatinib treatment in children and adolescents with chronic myeloid leukemia: Results from a phase III trial. Leukemia 2018, 32, 1657-1669. [CrossRef] [PubMed]

71. Kalmanti, L.; Saussele, S.; Lauseker, M.; Proetel, U.; Müller, M.C.; Hanfstein, B.; Schreiber, A.; Fabarius, A.; Pfirrmann, M.; Schnittger, S.; et al. Younger patients with chronic myeloid leukemia do well in spite of poor prognostic indicators: Results from the randomized CML study IV. Ann. Hematol. 2014, 93, 71-80. [CrossRef]

72. Millot, F.; Guilhot, J.; Suttorp, M.; Güneş, A.M.; Sedlacek, P.; De Bont, E.; Li, C.K.; Kalwak, K.; Lausen, B.; Culic, S.; et al. Prognostic discrimination based on the EUTOS long-term survival score within the International Registry for Chronic Myeloid Leukemia in children and adolescents. Haematologica 2017, 102, 1704-1708. [CrossRef] [PubMed]

73. Suttorp, M.; Knöfler, R.; Deutsch, H.; Paul, F.; Tiebel, O.; Metzler, M.; Millot, F. High Platelet Counts, Thrombosis, Bleeding Signs, and Acquired Von Willebrand Syndrome at Diagnosis of Pediatric Chronic Myeloid Leukemia (Abstract). Blood 2019, 134 (Suppl. S1), 4152. [CrossRef] 
74. Millot, F.; Maledon, N.; Guilhot, J.; Güneş, A.M.; Kalwak, K.; Suttorp, M. Favourable outcome of de novo advanced phases of childhood chronic myeloid leukaemia. Eur. J. Cancer. 2019, 115, 17-23. [CrossRef] [PubMed]

75. Hijiya, N.; Millot, F.; Suttorp, M. Chronic myeloid leukemia in children: Clinical findings, management, and unanswered questions. Pediatr. Clin North Am. 2015, 62, 107-119. [CrossRef]

76. Millot, F.; Facon, T.; Kerckaert, J.P.; Fenaux, P.; Lai, J.L.; Parent, M.; Bauters, F.; Jouet, J.P. Unusual recurrence of chronic myelogenous leukemia following bone marrow transplantation. Bone Marrow Transpl. 1991, 7, 393-395.

77. Magdy, M.; Abdel Karim, N.; Eldessouki, I.; Gaber, O.; Rahouma, M.; Ghareeb, M. Myeloid Sarcoma. Oncol. Res. Treat. 2019, 42, 224-229. [CrossRef]

78. Meyran, D.; Petit, A.; Guilhot, J.; Suttorp, M.; Sedlacek, P.; De Bont, E.; Li, C.K.; Kalwak, K.; Lausen, B.; Culic, S.; et al. Lymphoblastic predominance of blastic phase in children with chronic myeloid leukemia (CML) treated with imatinib: A report from the I-CML-Ped Study. Eur. J. Cancer 2020, 137, 224-234. [CrossRef]

79. Millot, F.; Baruchel, A.; Guilhot, J.; Petit, A.; Leblanc, T.; Bertrand, Y.; Mazingue, F.; Lutz, P.; Vérité, C.; Berthou, C.; et al. Imatinib is effective in children with previously untreated chronic myelogenous leukemia in early chronic phase: Results of the French national phase IV trial. J. Clin. Oncol. 2011, 29, 2827-2832. [CrossRef] [PubMed]

80. Castagnetti, F.; Gugliotta, G.; Baccarani, M.; Breccia, M.; Specchia, G.; Levato, L.; Abruzzese, E.; Rossi, G.; Iurlo, A.; Martino, B.; et al. Differences among young adults, adults and elderly chronic myeloid leukemia patients. Ann. Oncol. 2015, 26, 185-192. [CrossRef]

81. Knöfler, R.; Lange, B.S.; Paul, F.; Tiebel, O.; Suttorp, M. Bleeding signs due to acquired von Willebrand syndrome at diagnosis of chronic myeloid leukaemia in children. Br. J. Haematol. 2020, 188, 701-706. [CrossRef] [PubMed]

82. Chauhan, R.; Sazawal, S.; Singh, K.; Ragesh RNair, R.; Chhikara, S.; Deka, R.; Chaubey, R.; Veetil, K.K.; Dange, P.; Mahapatra, M.; et al. Reversal of Glanzmann thrombasthenia platelet phenotype after imatinib treatment in a pediatric chronic myeloid leukemia patient. Platelets 2018, 29, 203-206. [CrossRef]

83. Kurosawa, H.; Tanizawa, A.; Tono, C.; Watanabe, A.; Shima, H.; Ito, M.; Yuza, Y.; Hotta, N.; Muramatsu, H.; Okada, M.; et al. Leukostasis in Children and Adolescents with Chronic Myeloid Leukemia: Japanese Pediatric Leukemia/Lymphoma Study Group. Pediatr. Blood Cancer 2016, 63, 406-411. [CrossRef] [PubMed]

84. Chen, B.; Yan, X.; Zhang, X.; Yang, H. Leukostasis Retinopathy: An Uncommon Visual Threatening Complication of Chronic Myeloid Leukemia with Severe Hyperleukocytosis - A Case Report and Review of the Literature. Ind. J. Ophthalmol. 2018, 66, 1871-1874.

85. Becerra-Pedraza, L.C.; Jiménez-Martínez, L.E.; Peña-Morfin, I.; Nava-Esquivel, R.; Villegas-Martínez, J.A. Priapism as the initial sign in hematologic disease: Case report and literature review. Int. J. Surg. Case Rep. 2018, 43, 13-17. [CrossRef] [PubMed]

86. Rodgers, R.; Latif, Z.; Copland, M. How I manage priapism in chronic myeloid leukaemia patients. Br. J. Haematol. 2012, 158, 155-164. [CrossRef]

87. Sachdeva, P.; Kalra, M.; Thatikonda, K.B.; Aggarwal, S.K.; Sachdeva, D.; Sachdeva, A. Stuttering Priapism in a Teenage Boy: Lesson to be Learnt. J. Pediatr. Hematol. Oncol. 2020. Epub ahead of print. [CrossRef] [PubMed]

88. Acar, G.O.; Acioğlu, E.; Enver, O.; Ar, C.; Sahin, S. Unilateral sudden hearing loss as the first sign of chronic myeloid leukemia. Eur. Arch. Otorhinolaryngol. 2007, 264, 1513-1516. [CrossRef] [PubMed]

89. Giagounidis, A.A.; Burk, M.; Meckenstock, G.; Koch, A.J.; Schneider, W. Pathologic rupture of the spleen in hematologic malignancies: Two additional cases. Ann. Hematol. 1996, 73, 297-302. [CrossRef] [PubMed]

90. Drummond, D.; Lenoir, M.; Petit, A.Y. Splenic infarction in a child revealing chronic myeloid leukemia. Eur. J. Pediatr. 2012, 171, 1141-1142. [CrossRef] [PubMed]

91. Valent, P.; Horny, H.P.; Arock, M. The Underestimated Role of Basophils in Ph + Chronic Myeloid Leukaemia. Eur. J. Clin. Invest. 2018, 48, e13000. [CrossRef] [PubMed]

92. Weil, S.C.; Hrisinko, M.A. A hybrid eosinophilic-basophilic granulocyte in chronic granulocytic leukemia. Am. J. Clin. Pathol. 1987, 87, 66-70. [CrossRef] [PubMed]

93. Shinar, E.; Gershon, Z.L.; Leiserowitz, R.; Matzner, Y.; Yatziv, S.; Polliack, A. Coexistence of Gaucher disease and Philadelphia positive chronic granulocytic leukemia. Am. J. Hematol. 1982, 12, 199-202. [CrossRef]

94. Hussein, K.; Stucki-Koch, A.; Göhring, G.; Kreipe, H.; Suttorp, M. Increased megakaryocytic proliferation, pro-platelet deposition and expression of fibrosis-associated factors in children with chronic myeloid leukaemia with bone marrow fibrosis. Leukemia 2017, 31, 1540-1546. [CrossRef] [PubMed]

95. Dotti, G.; Garattini, E.; Borleri, G.; Masuhara, K.; Spinelli, O.; Barbui, T.; Rambaldi, A. Leucocyte alkaline phosphatase identifies terminally differentiated normal neutrophils and its lack in chronic myelogenous leukaemia is not dependent on p210 tyrosine kinase activity. Br. J. Haematol. 1999, 105, 163-172. [CrossRef]

96. Rambaldi, A.; Terao, M.; Bettoni, S.; Bassan, R.; Battista, R.; Barbui, T.; Garattini, E. Differences in the expression of alkaline phosphatase mRNA in chronic myelogenous leukemia and. paroxysmal nocturnal hemoglobinuria polymorphonuclear leukocytes. Blood 1989, 73, 1113-1115. [CrossRef]

97. Reid, A.G.; De Melo, V.A.; Elderfield, K.; Clark, I.; Marin, D.; Apperley, J.; Naresh, K.N. Phenotype of blasts in chronic myeloid leukemia in blastic phase-Analysis of bone marrow trephine biopsies and correlation with cytogenetics. Leuk. Res. 2009, 33, 418-425. [CrossRef] 
98. Advani, S.H.; Malhotra, H.; Kadam, P.R.; Iyer, R.S.; Nanjangud, G.; Balsara, B.; Saikia, T.; Gopal, R.; Nair, C.N. T-lymphoid blast crisis in chronic myeloid leukemia. Am. J. Hematol. 1991, 36, 86-92. [CrossRef]

99. Qing, X.; Qing, A.; Ji, P.; French, S.W.; Mason, H. Mixed phenotype (T/B/myeloid) extramedullary blast crisis as an initial presentation of chronic myelogenous leukemia. Exp. Mol. Pathol. 2018, 104, 130-133. [CrossRef]

100. Hochhaus, A.; Baccarani, M.; Silver, R.T.; Schiffer, C.; Apperley, J.F.; Cervantes, F.; Clark, R.E.; Cortes, J.E.; Deininger, M.W.; Guilhot, F.; et al. European LeukemiaNet 2020 recommendations for treating chronic myeloid leukemia. Leukemia 2020, 34, 966-984. [CrossRef]

101. Radich, J.P.; Deininger, M.; Abboud, C.N.; Altman, J.K.; Berman, E.; Bhatia, R.; Bhatnagar, B.; Curtin, P.; DeAngelo, D.J.; Gotlib, J.; et al. Chronic Myeloid Leukemia, Version 1.2019, NCCN Clinical Practice Guidelines in Oncology. J. Natl. Compr. Canc. Netw. 2018, 16, 1108-1135. [CrossRef] [PubMed]

102. Buesche, G.; Hehlmann, R.; Hecker, H.; Heimpel, H.; Heinze, B.; Schmeil, A.; Pfirrmann, M.; Gomez, G.; Tobler, A.; Herrmann, $\mathrm{H}$.; et al. Marrow fibrosis, indicator of therapy failure in chronic myeloid leukemia-Prospective long-term results from a randomized-controlled trial. Leukemia 2003, 17, 2444-2453. [CrossRef] [PubMed]

103. Buesche, G.; Ganser, A.; Schlegelberger, B.; von Neuhoff, N.; Gadzicki, D.; Hecker, H.; Bock, O.; Frye, B.; Kreipe, H. Marrow fibrosis and its relevance during imatinib treatment of chronic myeloid leukemia. Leukemia 2007, 21, 2420-2427. [CrossRef]

104. Hidalgo-López, J.E.; Kanagal-Shamanna, R.; Quesada, A.E.; Gong, Z.; Wang, W.; Hu, S.; Medeiros, L.J.; Bassett RLJr d'Orcy, E.; Yin, C.C.; Cortes, J.; et al. Bone marrow core biopsy in 508 consecutive patients with chronic myeloid leukemia: Assessment of potential value. Cancer 2018, 124, 3849-3855. [CrossRef]

105. Luu, M.H.; Press, R.D. BCR-ABL PCR testing in chronic myelogenous leukemia: Molecular diagnosis for targeted cancer therapy and monitoring. Expert Rev. Mol. Diagn. 2013, 13, 749-762. [CrossRef] [PubMed]

106. Burmeister, T.; Reinhardt, R. A multiplex PCR for improved detection of typical and atypical BCR-ABL fusion transcripts. Leuk Res. 2008, 32, 579-585. [CrossRef]

107. Möbius, S.; Schenk, T.; Himsel, D.; Maier, J.; Franke, G.N.; Saussele, S.; Pott, C.; Andrikovics, H.; Meggyesi, N.; Machova-Polakova, K.; et al. Results of the European survey on the assessment of deep molecular response in chronic phase CML patients during tyrosine kinase inhibitor therapy (EUREKA registry). J. Cancer Res. Clin. Oncol. 2019, 145, 1645-1650. [CrossRef] [PubMed]

108. Suttorp, M.; Bornhäuser, M.; Metzler, M.; Millot, F.; Schleyer, E. Pharmacology and pharmacokinetics of imatinib in pediatric patients. Expert Rev. Clin. Pharmacol. 2018, 11, 219-231. [CrossRef]

109. Cumbo, C.; Impera, L.; Minervini, C.F.; Orsini, P.; Anelli, L.; Zagaria, A.; Coccaro, N.; Tota, G.; Minervini, A.; Casieri, P.; et al Genomic BCR-ABL1 breakpoint characterization by a multi-strategy approach for "personalized monitoring" of residual disease in chronic myeloid leukemia patients. Oncotarget 2018, 9, 10978-10986. [CrossRef] [PubMed]

110. Machova Polakova, K.; Zizkova, H.; Zuna, J.; Motlova, E.; Hovorkova, L.; Gottschalk, A.; Glauche, I.; Koblihova, J.; Pecherkova, P.; Klamova, H.; et al. Analysis of chronic myeloid leukaemia during deep molecular response by genomic PCR: A traffic light stratification model with impact on treatment-free remission. Leukemia 2020, 34, 2113-2124. [CrossRef]

111. Pagani, I.S.; Dang, P.; Kommers, I.O.; Goyne, J.M.; Nicola, M.; Saunders, V.A.; Braley, J.; White, D.L.; Yeung, D.T.; Branford, S.; et al. BCR-ABL1 genomic DNA PCR response kinetics during first-line imatinib treatment of chronic myeloid leukemia. Haematologica 2018, 103, 2026-2032. [CrossRef]

112. Soverini, S.; de Benedittis, C.; Mancini, M.; Martinelli, G. Mutations in the BCR-ABLKinase Domain and Elsewhere in Chronic Myeloid Leukemia. Clin. Lymphoma Myeloma Leuk. 2015, 15, S120-S128. [CrossRef] [PubMed]

113. Branford, S.; Fletcher, L.; Cross, N.C.; Müller, M.C.; Hochhaus, A.; Kim, D.W.; Radich, J.P.; Saglio, G.; Pane, F.; Kamel-Reid, S.; et al. Desirable performance characteristics for BCR-ABL measurement on an international reporting scale to allow consistent interpretation of individual patient response and comparison of response rates between clinical trials. Blood 2008, 112, 3330-3338. [CrossRef] [PubMed]

114. Müller, M.C.; Cross, N.C.; Erben, P.; Schenk, T.; Hanfstein, B.; Ernst, T.; Hehlmann, R.; Branford, S.; Saglio, G.; Hochhaus, A. Harmonization of molecular monitoring of CML therapy in Europe. Leukemia 2009, 23, 1957-1963. [CrossRef] [PubMed]

115. Maia, R.C.; Vasconcelos, F.C.; Souza, P.S.; Rumjanek, V.M. Towards Comprehension of the ABCB1/P-Glycoprotein Role in Chronic Myeloid Leukemia. Molecules 2018, 23, 119. [CrossRef]

116. Bettoni da Cunha-Riehm, C.; Hildebrand, V.; Nathrath, M.; Metzler, M.; Suttorp, M. Vaccination with Live Attenuated Vaccines in Four Children With Chronic Myeloid Leukemia While on Imatinib Treatment. Front. Immunol. 2020, 11, 628. [CrossRef]

117. Rajala, H.L.M.; Missiry, M.E.; Ruusila, A.; Koskenvesa, P.; Brümmendorf, T.H.; Gjertsen, B.T.; Janssen, J.; Lotfi, K.; Markevärn, B.; Olsson-Strömberg, U.; et al. Tyrosine kinase inhibitor therapy-induced changes in humoral immunity in patients with chronic myeloid leukemia. J. Cancer Res. Clin. Oncol. 2017, 143, 1543-1554. [CrossRef]

118. Totadri, S.; Thipparapu, S.; Aggarwal, R.; Sharma, M.; Naseem, S.; Jain, R.; Trehan, A.; Malhotra, P.; Varma, N.; Bansal, D. ImatinibInduced Hypogammaglobulinemia in Children and Adolescents with Chronic Myeloid Leukemia. Pediatr. Hematol. Oncol. 2020, 4, 1-6. [CrossRef]

119. Adnan Awad, S.; Kankainen, M.; Ojala, T.; Koskenvesa, P.; Eldfors, S.; Ghimire, B.; Kumar, A.; Kytölä, S.; Kamel, M.M.; Heckman, C.A.; et al. Mutation accumulation in cancer genes relates to nonoptimal outcome in chronic myeloid leukemia. Blood Adv. 2020, 4, 546-559. [CrossRef] 
120. Egan, D.; Radich, J. Making the diagnosis, the tools, and risk stratification: More than just BCR-ABL. Best Pr. Res Clin Haematol. 2016, 29, 252-263. [CrossRef] [PubMed]

121. Gambacorti-Passerini, C.; Zucchetti, M.; Russo, D.; Frapolli, R.; Verga, M.; Bungaro, S.; Tornaghi, L.; Rossi, F.; Pioltelli, P.; Pogliani, E.; et al. Alpha1 acid glycoprotein binds to imatinib (STI571) and substantially alters its pharmacokinetics in chronic myeloid leukemia patients. Clin. Cancer Res. 2003, 9, 625-632.

122. Koschmieder, S.; Vetrie, D. Epigenetic dysregulation in chronic myeloid leukaemia: A myriad of mechanisms and therapeutic options. Semin. Cancer Biol. 2018, 51, 180-197. [CrossRef]

123. Pfirrmann, M.; Lauseker, M.; Hoffmann, V.S.; Hasford, J. Prognostic scores for patients with chronic myeloid leukemia under particular consideration of competing causes of death. Ann. Hematol. 2015, 94 (Suppl. S2), S209-S218. [CrossRef] [PubMed]

124. Millot, F.; Guilhot, J.; Baruchel, A.; Petit, A.; Bertrand, Y.; Mazingue, F.; Lutz, P.; Vérité, C.; Berthou, C.; Galambrun, C.; et al. Impact of early molecular response in children with chronic myeloid leukemia treated in the French Glivec phase 4 study. Blood 2014, 124, 2408-2410. [CrossRef]

125. Baccarani, M.; Rosti, G.; Soverini, S. Chronic myeloid leukemia: The concepts of resistance and persistence and the relationship with the BCR-ABL1 transcript type. Leukemia 2019, 33, 2358-2364. [CrossRef]

126. Molica, M.; Abruzzese, E.; Breccia, M. Prognostic Significance of Transcript-Type BCR - ABL1 in Chronic Myeloid Leukemia. Mediterr J. Hematol. Infect. Dis. 2020, 12, e2020062. [CrossRef]

127. Suttorp, M.; Thiede, C.; Tauer, J.T.; Range, U.; Schlegelberger, B.; von Neuhoff, N. Impact of the type of the BCR-ABL fusion transcript on the molecular response in pediatric patients with chronic myeloid leukemia. Haematologica 2010, 95, 852-853. [CrossRef] 